\title{
Asset Price Learning and Optimal Monetary Policy
}

Caines, Colin and Fabian Winkler
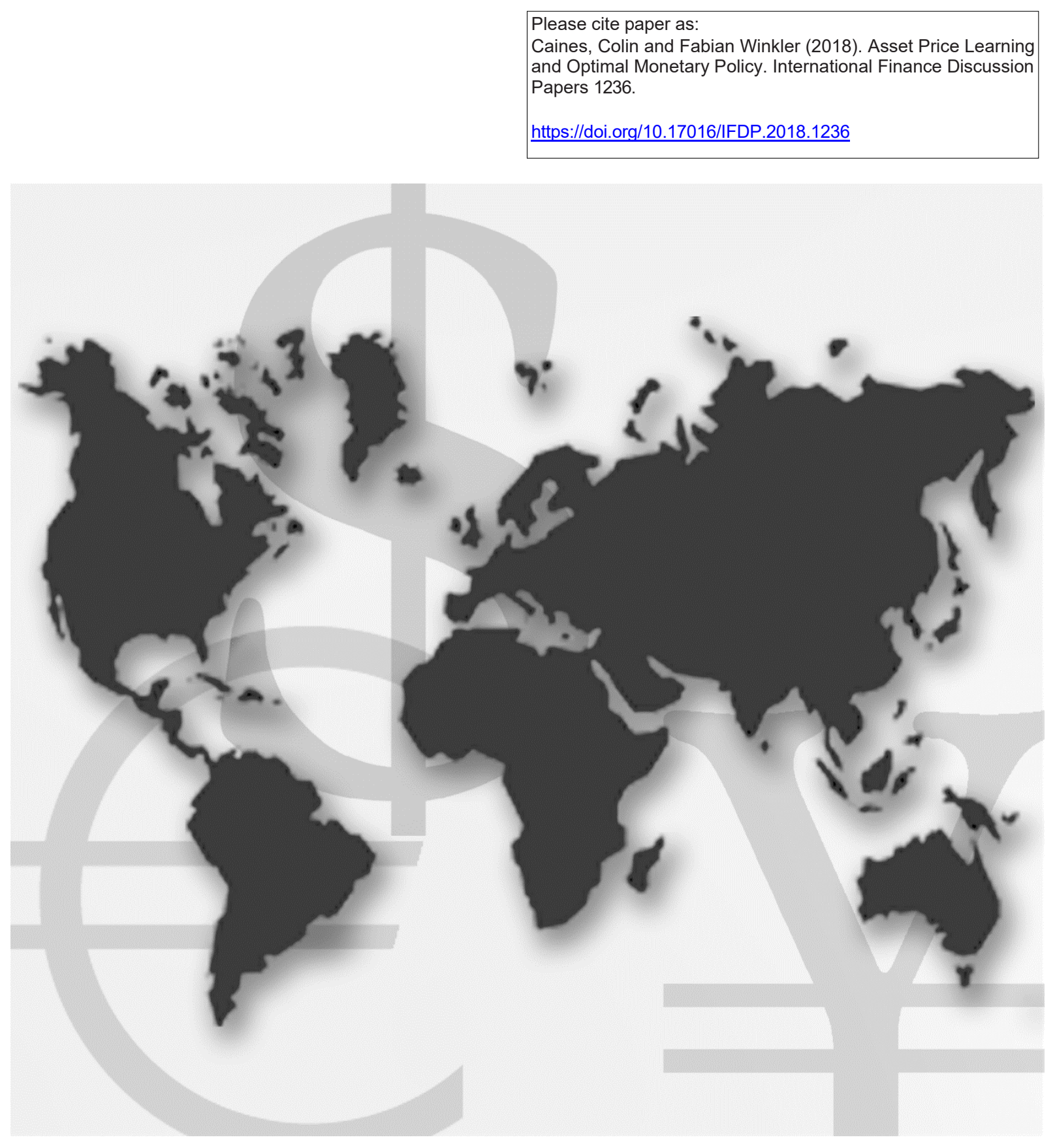

\section{International Finance Discussion Papers}

Board of Governors of the Federal Reserve System

Number 1236

August 2018 
Board of Governors of the Federal Reserve System

International Finance Discussion Papers

Number 1236

August 2018

Asset Price Learning and Optimal Monetary Policy

Colin Caines and Fabian Winkler

NOTE: International Finance Discussion Papers are preliminary materials circulated to stimulate discussion and critical comment. References to International Finance Discussion Papers (other than an acknowledgment that the writer has had access to unpublished material) should be cleared with the author or authors. Recent IFDPs are available on the Web at www.federalreserve.gov/pubs/ifdp/. This paper can be downloaded without charge from Social Science Research Network electronic library at www.ssrn.com. 


\title{
Asset Price Learning And Optimal Monetary Policy
}

\author{
Colin Caines* \& Fabian Winkler ${ }^{\dagger} \S$
}

\begin{abstract}
We characterize optimal monetary policy when agents are learning about endogenous asset prices. Boundedly rational expectations induce inefficient equilibrium asset price fluctuations which translate into inefficient aggregate demand fluctuations. We find that the optimal policy raises interest rates when expected capital gains, and the level of current asset prices, is high. The optimal policy does not eliminate deviations of asset prices from their fundamental value. When monetary policymakers are information-constrained, optimal policy can be reasonably approximated by simple interest rate rules that respond to capital gains. Our results are robust to a wide range of belief specifications as well as to the inclusion of an investment channel.
\end{abstract}

Keywords: Optimal Monetary Policy, Natural Real Interest Rate, Learning, Asset Price Volatility, Leaning Against The Wind

JEL classifications: E44, E52

* The author is a staff economist in the Division of International Finance, Board of Governors of the Federal Reserve System, Washington, D.C. 20551 U.S.A. The email address of the author is colin.c.caines@frb.gov.

$\dagger$ The author is a staff economist in the Division of Monetary Affairs, Board of Governors of the Federal Reserve System, Washington, D.C. 20551 U.S.A. The email address of the author is fabian.winkler@frb.gov.

$\S$ The views in this paper are solely the responsibility of the authors and should not be interpreted as reflecting the views of the Board of Governors of the Federal Reserve System or of any other person associated with the Federal Reserve System. The authors would like to thank Chris Gust, Damjan Pfajfar, Chris Erceg, Kevin Lansing, Thomas Mertens, Robert Tetlow, Pei Kuang, and seminar participans at the Chicago Fed, the San Francisco Fed, Drexel University, the 2018 Midwest Macro conference, the 2018 Canadian Economics Assocation Meetings, the 2018 Econometric Society Summer Meeting and the University of Birmingham for helpful comments. 


\section{Introduction}

How, if at all, should monetary policy react to asset prices? This question has been debated in the macroeconomic literature at least since the seminal article of Bernanke and Gertler (2001). Some economists argue that monetary policy should not pay attention at all to asset prices, or at most in order to improve forecasts of inflation and economic activity. Others argue that asset price misalignments can pose significant risks to macroeconomic and financial stability, and that monetary policy should at least in some circumstances raise interest rates in response to asset price increases.

It emerges relatively quickly that any answer to this question depends on what one thinks about the sources of asset price fluctuations. Are assets always priced at their fundamental value, and if not, what is the nature of price misaligments? Standard macroeconomic models, including workhorse New-Keynesian models used for monetary policy analysis, rule out asset price misalignments by design, and are therefore of limited use in such an exercise. Recently, Gali (2014, 2017) has added rational bubbles to these models. He cautions against a positive reaction of interest rates to bubbles because bubbles grow faster when interest rates are raised. Consistent with that intuition, Dong et al. (2017) find that a negative reaction of interest rates to asset prices is optimal in a model with liquidity bubbles in the presence of collateral constraints. Yet, rational bubbles are not the only way through which asset prices can deviate from their "fundamental value". An alternative and indeed prominent narrative of price misalignments holds that investors have boundedly rational expectations and suffer from bouts of over- and underconfidence which affect prices. This narrative has been formalized using learning models, which are a plausible explanation for many well-known asset price characteristics (Fuster et al. 2012; Collin-Dufresne et al. 2013; Adam et al. 2015; Barberis et al. 2015 for stock prices; Adam et al. (2012); Caines (2016); Glaeser and Nathanson (2017) for house prices), and are consistent with survey measures of return expectations that are at odds with rational expectations models (Greenwood and Shleifer, 2014). However, very little work exists on how boundedly rational asset price expectations affect optimal monetary policy.

In this paper, we consider a model in which agents hold subjective, boundedly rational beliefs about asset prices and update these beliefs through a learning process. The model is a simple New-Keynesian model, to which we add a durable asset in fixed supply and learning about the equilibrium asset price. The learning process implies extrapolative expectations, which can lead to endogenous boom-bust cycles in equilibrium price dynamics. We isolate the effects of asset price learning from other expectational channels by restricting beliefs to be model-consistent conditional on subjective asset price expectations 
(Winkler, 2016), implying that expectations are consistent with all equilibirum conditions other than asset market clearing. ${ }^{1}$ This restriction greatly reduces the degrees of freedom in boundedly rational expectations and also renders the analysis of the learning model particularly transparent. In particular, it implies that agents fully understand the policy strategy followed by the central bank. We then solve analytically for optimal monetary policy under learning.

We show that the optimal policy requires the policy rate to respond positively to asset prices, separately from its reaction to fundamental shocks. The reason is that the natural real rate of interest under learning is no longer a function of just technology and preferences, but depends on subjective asset price beliefs. If agents expect larger capital gains on their assets, then the real interest rate must rise also for the bond market to clear, even if expectations aren't rational. When prices are rigid, setting the interest rate below this "perceived natural rate" inefficiently raises aggregate demand and inflation. The central bank therefore needs to raise interest rates when asset prices are high in order to stabilize inflation. While the optimal interest rate policy is different under learning, the optimal target criterion is not: Because price rigidities are the only distortion in our baseline model, flexible inflation targeting remains optimal. We also numerically evaluate simple Taylor-type interest rate rules which include a reaction to asset prices. We find that this reaction generally mitigates the distortions from non-rational beliefs and stabilizes asset price fluctuations. This latter finding is in direct contrast to Gali (2014) and Dong et al. (2017): Higher interest rates increase the size of rational bubbles, but decrease subjective price expectations under learning.

The model predicts positve comovement between the natural real interest rate and realized asset prices. Such comovement seems to be present in the data as well, as Figure 1 shows. The figure plots the 20-quarter change in the well-known Laubach and Williams (2016) natural rate estimate against the 20-quarter change in both the FHFA house price index for the United States as well as the Shiller CAPE ratio ${ }^{2}$. House prices and the natural real rate are positively correlated in both cases.

In our baseline version of the model, non-rational asset price expectations cause distortions because they affect perceived household wealth and therefore aggregate demand. There are of course other, and potentially more important channels through which asset prices can affect the real economy, e.g. credit frictions (Bean, 2004). We see the wealth effect channel in this paper as a stand-in for these more complex transmission channels of asset prices. The advantage of this simplification is that we are able to obtain closed form solutions for optimal monetary policy in the presence of learning. But

\footnotetext{
${ }^{1}$ The concept has also been applied in Caines (2016) and Gandré (2017).

${ }^{2}$ We thank Kevin Lansing for pointing out this relationship to us.
} 
Figure 1: 20-Quarter Change in the Natural Rate of Interest \& Asset Prices.
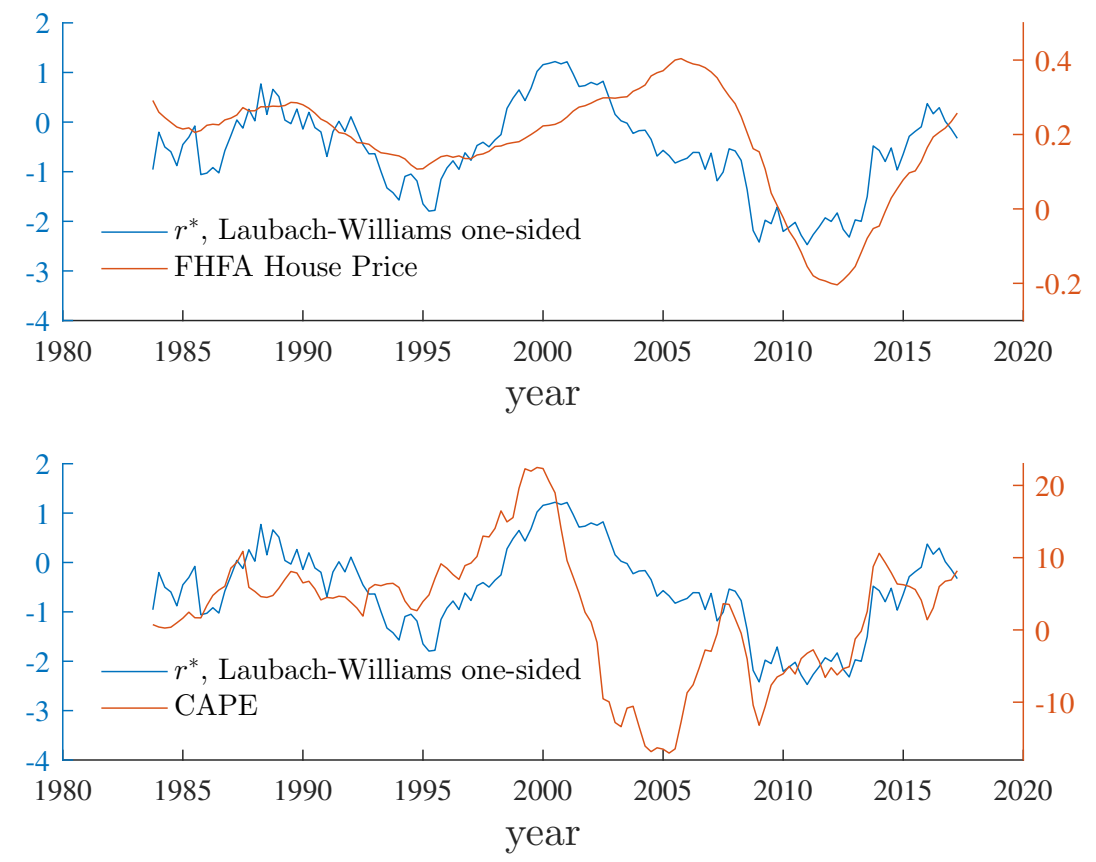

we also consider an extension of our model in which asset supply is elastic. In this case, subjective belief distortions also cause inefficient fluctuations in real investment. Numerical simulations indicate that interest rate rules still need to respond to asset prices in this case; and moreoever, that even the optimal target criterion features "leaning against the wind", in the sense that the central bank tolerates a downward departure of inflation from the target at times when asset prices are high.

Our baseline model also assumes a particular process of expectation formation in which agents think that asset prices are a random walk with a small time-varying drift. This simple process has been shown to lead to good asset pricing properties in equilibrium (Adam et al., 2017), but our results are not confined to the use of this process. We show that our results carry through to more general class of subjective beliefs, which include for example "natural expectations" (Fuster et al., 2012) and "diagnostic expectations" (Bordalo et al., 2018).

The remainder of this paper is structured as follows. After discussing the related literature in Section 2, we begin by describing the model in Section 3, and our notion of a learning equilibrium in Section 4. We characterize the linearized equilibrium under rational expectations and learning in Section 5. Optimal policy is analyzed in Sections 6, while Section 7 discusses how well certain simple interest rate rules approximate the optimal policy. Sections 8 and 9 discuss extensions to more general beliefs and an invenstment channel, respectively. Section 10 concludes. 


\section{Related literature}

Our paper shares a number of features with Adam and Woodford (2018), who study so-called robustly optimal policy with house prices. Their model is very similar to ours, but instead of learning they study belief distortions to the fundamentals of the economy and let the policymaker choose a policy that maximizes welfare for the worst possible combination of these distortions. ${ }^{3}$ The appeal of such an analysis is that the policymaker cannot systematically exploit distorted expectations to its advantage, because the class of possible distortions is large and the policymaker does not know which of these is realized. In our setup, the policymaker could in principle achieve outcomes that are far better than those under rational expectations with a suitable, highly non-linear policy. Because we judge such sophisticated manipulation of beliefs to be unrealistic, we restrict the set of admissible policies to simple linear targeting and instrument rules. Moreover, our results are derived at the fully efficient steady state. By contrast, Adam and Woodford find a tightening reaction of monetary policy to rising asset prices to be beneficial only when the steady state is distorted in a particular direction.

Our analysis also shares some features with Christiano et al. (2010), who study the optimal policy reaction to news shocks about future productivity. In their model, news shocks cause asset prices to rise, and also increase the natural real rate of interest, so that monetary policy should optimally respond by raising interest rates. In this paper, the natural real rate fluctuates in response to endogenous changes in subjective expectations that can be entirely independent of productivity.

Dupor (2005) and Mertens (2011), among others, have argued that monetary policy should react to asset prices in environments that depart from rational expectations. In these papers, distortions to beliefs about asset prices have real effects through investment channels. Monetary policy that reacts to asset prices can then counteract these effects. In this paper we present an argument for leaning against the wind even in the absence of distortions of this kind. Our results are only strengthened if we include an investment channel.

Our paper focuses on learning about asset prices but keeps expectations conditionally modelconsistent otherwise. This is not to say that learning or other belief distortions in expectations of other variables doesn't matter; rather, it allows us to isolate the effects of asset prices learning from other such distortions. In so doing, we complement a small but growing number of papers studying monetary policy prescriptions in models with learning about inflation. Fully optimal policy has recently

\footnotetext{
${ }^{3}$ One important difference between the different concepts of belief distortions is that our asset prices can deviate from the discounted sum of expected fundamentals, whereas in Adam and Woodford (2018) only expectations of fundamentals are distorted.
} 
been studied in a two-equation model with learning by Molnar and Santoro (2014) and Eusepi and Preston (2016). Airaudo (2016) aguments the standard New Keynesian model with a stock market and infinite-horizon learning (as in Preston (2006)) to study conditions under which the rational expectations equilibrium is learnable, but stops short of characterizing optimal policy. ${ }^{4}$ Eusepi et al. (2015) introduce drift in long-run expectations to a New Keynesian model and show that such beliefs introduce an intertemporal trade-off in policy between stablizing current inflation and anchoring long-horizon beliefs.

\section{Model description}

Our model is a standard New-Keynesian model in which the representative household also holds a stock of an asset that yields utility. The supply of the asset in the economy is fixed. One can think of the asset as a stock of housing, but we will refer to it as a generic durable asset. Because the asset is in fixed supply, the dynamics of inflation and output are unaffected by its presence under rational expectations. Under learning, however, we will get non-trivial effects of asset prices on allocations.

We first describe the model for a general description of expectations. A representative household provides labor and owns firms. It can also hold nominal bonds promising a nominal return $i_{t}$. In addition, the household owns the durable asset. The household's problem is

$$
\begin{gathered}
\mathbb{E}^{\mathcal{P}} \sum_{t=0}^{\infty} \beta^{t}\left(\frac{C_{t}^{1-\gamma}}{1-\gamma}-\frac{N_{t}^{1+\phi}}{1+\phi}+\chi \frac{H_{t}^{1-\theta}}{1-\theta}\right) \\
\text { s.t. } C_{t}=W_{t} N_{t}+\Pi_{t}+T_{t}-Q_{t}\left(H_{t}-H_{t-1}\right)+B_{t}-\frac{1+i_{t-1}}{1+\pi_{t}} B_{t-1} .
\end{gathered}
$$

Here, $C_{t}$ is the household's utility from consuming final consumption goods, $N_{t}$ is the household's labor supply, and $T_{t}$ are lump-sum taxes. $\Pi_{t}$ are the profits received from firms. The quantity of the asset owned by the household is denoted $H_{t}$ and trades at the price $Q_{t} . B_{t}$ are government bonds which are in zero net supply. The price level is $P_{t}$ and $\pi_{t}=P_{t} / P_{t-1}-1$ is the inflation rate. The expectational operator $\mathbb{E}^{\mathcal{P}}$ has a superscript indicating that agents' expectations are evaluated under a subjective probability measure $\mathcal{P}$ that need not coincide with rational expectations.

\footnotetext{
${ }^{4}$ Outside of the learning literature, Gabaix (2016) develops a particular form of myopia and studies optimal policy under commitment. In his model, agents have attenuation bias and underestimate the persistence of economic fluctuations. In this paper, agents instead overestimate their persistence, at least along the dimension of asset prices. As a result, the optimal policy needs to react aggressively to the extrapolative bias, while Gabaix finds that policy can afford to be less aggressive in the presence of attenuation bias.
} 
The first order conditions are:

$$
\begin{aligned}
W_{t} & =C_{t}^{\gamma} N_{t}^{\phi} \\
1 & =\beta \mathbb{E}_{t}^{\mathcal{P}}\left(\frac{C_{t}}{C_{t+1}}\right)^{\gamma} \frac{1+i_{t}}{1+\pi_{t+1}} \\
Q_{t} & =\chi \frac{C_{t}^{\gamma}}{H_{t}^{\theta}}+\beta \mathbb{E}_{t}^{\mathcal{P}}\left(\frac{C_{t}}{C_{t+1}}\right)^{\gamma} Q_{t+1} .
\end{aligned}
$$

On the production side, a representative intermediate goods producer transforms household labor into intermediate goods using the decreasing returns to scale technology

$$
\tilde{Y}_{t}=A_{t} N_{t}^{\alpha}
$$

It has to hire labor at the real wage rate $w_{t}$ and sells its goods at the real price $M_{t}$. Its first-order condition is

$$
W_{t}=\alpha M_{t} A_{t} N_{t}^{\alpha-1}
$$

There is a contiuum of wholesalers indexed by $i \in[0,1]$ who transform the undifferentiated intermediate good into differentiated goods using a one-for-one technology. They face a standard Dixit-Stiglitz demand function and a Calvo price setting friction. When producer $i$ is able to set a price $P_{i t}$ for its output $Y_{i t}$, it solves:

$$
\begin{gathered}
\max _{P_{i t}} \mathbb{E}_{t}^{\mathcal{P}} \sum_{s=0}^{\infty}\left(\prod_{\tau=1}^{s} \xi \Lambda_{t, t+\tau}\right)\left(\left(1+\tau_{t}\right) P_{i t}-M_{t+s} P_{t+s}\right) Y_{i t+s} \\
\text { s.t. } Y_{i t}=\left(\frac{P_{i t}}{P_{t}}\right)^{-\sigma} Y_{t},
\end{gathered}
$$

where $\sigma$ is the demand elasticity of substitution between varieties, $\Lambda_{t, t+\tau}=\beta^{\tau} C_{t}^{\gamma} C_{+\tau}^{-\gamma}$ is the household discount factor between times $t$ and $t+\tau, \xi$ is the probability of not being able to adjust the price in the futureAny profits are distributed to households. The first-order conditions are standard and give rise to the New-Keynesian Phillips curve.

The term $\tau_{t}$ is a time-varying government subsidy to revenue. Shocks to the subsidy will act as costpush shocks. The steady-state value of the subsidy is set such that it eliminates mark-up distortions. Our steady state is therefore fully efficient.

A representative retailer buys differentiated goods from wholesalers at the price $P_{i t}$ and transforms them back into a homogenous final consumption good. The final good sells at price $P_{t}$ and is produced 
according to the technology

$$
Y_{t}=\left(\int_{0}^{1}\left(Y_{i t}\right)^{\frac{\sigma-1}{\sigma}} d i\right)^{\frac{\sigma}{\sigma-1}} .
$$

The first order condition gives rise to a constant elasticity of substitution $\sigma$ between varieties. The price level can be expressed as $P_{t}=\int_{0}^{1} P_{i t} Y_{i t} / Y_{t}$.

The government transfers a lump sum real amount to households

$$
T_{t}=\tau_{t} \int_{0}^{1} P_{i t} Y_{i t} d i
$$

to finance the subsidies to final good producers and offset the tax on stock holdings. Profits and government transfers sum up to $\Pi_{t}+T_{t}=Y_{t}-W_{t} N_{t}$. Finally, the central bank sets the nominal interest rate.

We allow for productivity and cost-push shocks which follows first-order autoregressive processes:

$$
\begin{aligned}
\log A_{t} & =\left(1-\rho_{a}\right) \log \bar{A}+\rho_{a} \log A_{t-1}+\varepsilon_{a t} \\
\tau_{t} & =\left(1-\rho_{\tau}\right) \bar{\tau}_{t}+\rho_{\tau} \tau_{t-1}+\varepsilon_{\tau t}
\end{aligned}
$$

The innovations are independent white noise with variances $\sigma_{A}^{2}$ and $\sigma_{\tau}^{2}$.

Market clearing in the final goods market requires $Y_{t}=C_{t}$. Bonds are in zero net supply and the market clearing condition is therefore $B_{t}=0$. Finally, the supply of the durable is fixed at unity, so that asset market clearing requires $H_{t}=1$.

\section{Equilibrium}

The equilibrium under rational expectations is standard - it is the textbook New Keynesian model. The asset price $Q_{t}$ is redundant because the durable asset is in fixed supply. Agents with rational expectations never expect to buy or sell the asset, not because they expect to be unable to to do so - they are price takers in a competitive market - but because they expect the price in every state of the world to be such that they will not ever want to change their asset holdings.

Let's recall the formal definition of a rational expectations equilibrium. Let $y_{t} \in \mathbb{R}^{N}$ denote the collection of all endogenous model variables - including prices, allocations, and strategies - and by $u_{t} \in$ $\mathbb{R}^{M}$ the collection of all exogenous model variables at time $t$, which I will call "fundamentals". Stochastic processes for $y_{t}$ and $u_{t}$ are defined on the spaces $\Omega_{y}=\prod_{t=0}^{\infty} \mathbb{R}^{N}$ and $\Omega_{u}=\Pi_{t=0}^{\infty} \mathbb{R}^{M}$, respectively. Further, 
denote by $\Omega_{u}^{(t)}$ the set of all possible histories of exogenous variables up to period $t$, and its elements by $u^{(t)} \in \Omega_{u}^{(t)}$. Finally, let $\mathbb{P}_{u}$ denote the true probability measure for the exogenous variables defined on $\left(\Omega_{u}, \mathcal{S}\left(\Omega_{u}\right)\right)$, where $\mathcal{S}(\cdot)$ is the Borel sigma-algebra on a metric space. The topological support of $\mathbb{P}_{u}$ is denoted bysupp $\left(\mathbb{P}_{u}\right)$.

Definition 1. A rational expectations equilibrium is a sequence of mappings $g_{t}: \Omega_{u}^{(t)} \ni u^{(t)} \mapsto y_{t} \in$ $\mathbb{R}^{N}, t=0,1,2, \ldots$ such that, for all $t$ and $u^{(t)} \in \operatorname{supp}\left(\mathbb{P}_{u}\right)$ :

1. the choices contained in $y_{t}$ solve the time- $t$ decision problem of each agent in the economy, conditional on decision-relevant ${ }^{5}$ past and current outcomes contained in $u^{(t)}$ and $y^{(t)}=\left(g_{0}\left(u^{(0)}\right), \ldots, g_{t}\left(u^{(t)}\right)\right)$, and evaluating the probability of future external decision-relevant outcomes under the probability measure $\mathbb{P}$ implied by $\mathbb{P}_{u}$ and the mappings $\left(g_{t}\right)_{t=0}^{\infty}$;

2. the allocations contained in $y_{t}=g_{t}\left(u^{(t)}\right)$ clear all markets.

Under learning, we assume that agents are not endowed with the knowledge of the equilibrium asset price process. Intuitively, they do not know whether only the representative household is investing in the asset, or whether other investors exist who trade in unknown ways, causing seemingly random price fluctuations. Faced with this lack of knowledge, agents forecast prices using a subjective belief system. As we show in Section 8, this subjective belief system can be made quite general, but here we confine ourselves to our preferred specification which follows Adam et al. (2017). Agents think that the asset price is a simple random walk model with a time-varying drift:

$$
\begin{aligned}
\Delta \log Q_{t} & =\mu_{t-1}+\varepsilon_{t} \\
\mu_{t} & =\rho_{\mu} \mu_{t-1}+\nu_{t} .
\end{aligned}
$$

where the shocks $\varepsilon_{t} \sim \mathcal{N}\left(0, \sigma_{\varepsilon}^{2}\right)$ and $\nu_{t} \sim \mathcal{N}\left(0, \sigma_{\nu}^{2}\right)$ are iid white noise, independent of the rest of the economy. Since these two shocks are not observable, agents have to use the Kalman filter to form a belief about the hidden state $\mu_{t}$. The asset price can equivalently be written just in terms of observables and the filtered state:

$$
\begin{aligned}
\Delta \log Q_{t} & =\hat{\mu}_{t-1}+z_{t} \\
\hat{\mu}_{t} & =\rho_{\mu} \hat{\mu}_{t-1}+g z_{t}
\end{aligned}
$$

Here, $\hat{\mu}_{t}$ is the belief about $\mu_{t} ; g$ is the weight agents place on new data when updating their beliefs,

\footnotetext{
${ }^{5} \mathrm{~A}$ variable is decision-relevant if it enters the agents' decision problem, and a decision-relevant variable is external if its value is taken as given by the agent, while it is internal if the variable is part of the solution of the agents' decision problem. For example, wholesalers need to get information on current and future aggregate demand $Y_{t}$ (decision-relevant and external) to set prices $P_{i t}$ (decision-relevant and internal), while they do not need to forecast wages since their only production input is the intermediate good.
} 
which is a function of the perceived variances of $\varepsilon_{t}$ and $\nu_{t}$; and $z_{t} \sim \mathcal{N}\left(0, \sigma_{z}^{2}\right)$ is the forecasting error in the filtering problem. This forecasting error is exogenous normally distributed white noise under agents' subjective expectation, the variance of which is decreasing in the signal-to-noise ratio $\sigma_{\nu}^{2} / \sigma_{\varepsilon}^{2}$. In order to avoid complications arising from simultaneity in the determination of outcomes and beliefs, we follow Adam et al. (2012) and Caines (2016) and assume that in period $t$ agents make choices conditional on $\hat{\mu}_{t-1}$, and update their beliefs according to (12) at the end period.

In order to determine expectations about the remaining variables of the model, including inflation, we follow Winkler (2016) in assuming that agents have so-called "conditionally model-consistent expectations". This is a restriction on expectations that effectively allows us to isolate the effects of asset price learning from other potential sources of learning in the economy. Conditionally model-consistent expectations are consistent with all equilibrium conditions of the model, except those that would convey knowledge of the price that clears the asset market.

Formally, let $\left(\Omega_{z}, \mathcal{S}\left(\Omega_{z}\right), \mathcal{P}_{z}\right)$ be the probability space that defines the subjective beliefs for $z_{t}$ (i.e., the $z_{t}$ are iid normally distributed with mean zero and variance $\sigma_{z}^{2}$ ). Agents' subjective beliefs depend on this perceived stochastic forecast error even though in equilibrium, model outcomes are a function only of fundamentals $u_{t}$. The subjective probability measure $\mathcal{P}$ is defined by a mapping from fundamentals $u_{t}$ and the subjective forecast error $z_{t}$ to model outcomes $y_{t}$.

Definition 2. Conditionally model-consistent expectations (CMCE) are a sequence of mappings $h_{t}$ : $\Omega_{u}^{(t)} \times \Omega_{z}^{(t)} \ni\left(u^{(t)}, z^{(t)}\right) \mapsto y_{t} \in \mathbb{R}^{N}, t=0,1,2, \ldots$ such that, for all $t$ and $\left(u^{(t)}, z^{(t)}\right) \in \operatorname{supp}\left(\mathcal{P}_{u, z}\right)$ :

1. the choices contained in $y_{t}$ solve the time- $t$ decision problem of each agent in the economy, conditional on decision-relevant past and current outcomes contained in $u^{(t)}$ and $y^{(t)}=\left(h_{0}\left(u^{(0)}, z^{(0)}\right), \ldots, h_{t}\left(u^{(t)}, z^{(t)}\right)\right)$, and evaluating the probability of future decision-relevant outcomes under the probability measure $\mathcal{P}$ implied by $\mathbb{P}_{u} \otimes \mathcal{P}_{z}$ and the mappings $\left(h_{t}\right)_{t=0}^{\infty}$;

2. the allocations contained in $y_{t}=h_{t}\left(u^{(t)}, z^{(t)}\right)$ clear all markets except the markets for assets and final consumption goods;

3. asset prices under $\mathcal{P}$ follow the law of motion given by (12)-(13).

The definition of the mappings $h_{t}$ defining expectations is almost identical to the definition of a rational expectations equilibrium, except that asset market equilibrium is not part of the conditions, and instead the price $Q_{t}$ evolves according to subjective beliefs. Conditional model consistency restricts the subjective belief $\mathcal{P}$ to have the maximum degree of consistency with the model given agents' misspecified belief about asset prices. In analogy to the adaptive learning literature, we call the mappings $h_{t}$ defining beliefs the perceived law of motion (PLM).

Computing the learning equilibrium is an easy two-step procedure: First, compute the PLM 
$h_{t}\left(u^{(t)}, z^{(t)}\right)$; second, compute the ALM $g_{t}\left(u^{(t)}\right)$. Both steps are no more complicated than solving the rational expectations equilibrium.

While under $\mathcal{P}$, demand for the durable asset does not have to be equal to supply, in equilibrium the market still has to clear:

Definition 3. An equilibrium with conditionally model-consistent expectations is a sequence of mappings $r_{t}: \Omega_{u}^{(t)} \ni u^{(t)} \mapsto z_{t} \in \mathbb{R}$ and $g_{t}: \Omega_{u}^{(t)} \ni u^{(t)} \mapsto y_{t} \in \mathbb{R}^{N}, t=0,1,2, \ldots$ such that, for all $t$ and $u^{(t)} \in \operatorname{supp}\left(\mathbb{P}_{u}\right):$

1. $g\left(u^{(t)}\right)=h\left(u^{(t)},\left(r_{0}\left(u^{(0)}\right), \ldots, r_{t}\left(u^{(t)}\right)\right)\right)$;

2. the allocations contained in $y_{t}=g_{t}\left(u^{(t)}\right)$ clear the asset market.

Market clearing is brought about by finding the right value of the price $Q_{t}$ that clears the housing market. We call the resulting equilibrium mappings $g_{t}$ the actual law of motion (ALM). This mapping implies a particular path for $z_{t}$, the subjective house price forecast error. In equilibrium, $z_{t}$ will be a function of the states and the shocks of the model, while under $\mathcal{P}$ it is perceived as an unforecastable exogenous disturbance. It is precisely in this way that $\mathcal{P}$ violates the rational expectations hypothesis.

Agents endowed with conditionally model-consistent expectations may not know the equilibrium pricing function, but they make the smallest possible expectational errors consistent with their subjective view about the evolution of stock prices. This way of setting up expectations is very tractable and can be readily applied in a variety of models, as we have shown in previous papers (Caines, 2016; Winkler, 2016). It also allows us to transparently solve the linearized version of the model.

\section{$5 \quad$ Linearized equilibrium}

The analysis in this paper will focus entirely on the linearized version of the model. The conditionally model-consistent expectations under learning imply that the learning equilibrium can be linearized in much the same way as its rational expectations counterpart. 


\subsection{Rational expectations equilibrium}

Under rational expectations, we can linearize around the non-stochastic steady state to obtain:

$$
\begin{aligned}
y_{t} & =a_{t}+\alpha n_{t} \\
\pi_{t} & =\beta \mathbb{E}_{t} \pi_{t+1}+\frac{(1-\xi)(1-\beta \xi)}{\xi}\left(w_{t}-a_{t}+(1-\alpha) n_{t}\right)+\eta_{t} \\
w_{t} & =\gamma y_{t}+\phi n_{t} \\
i_{t} & =\gamma\left(\mathbb{E}_{t} y_{t+1}-y_{t}\right)+\mathbb{E}_{t} \pi_{t+1} \\
q_{t} & =\gamma y_{t}-\beta \gamma \mathbb{E}_{t} y_{t+1}+\beta \mathbb{E}_{t} q_{t+1} .
\end{aligned}
$$

Here, lower-case variables denote log-linearizations around the zero-inflation steady state, except for $i_{t}$ which is the difference of the nominal interest rate from its steady-state level, and $\eta_{t}=\frac{(1-\xi)(1-\beta \xi)}{\xi}\left(\bar{\tau}-\tau_{t}\right)$ is the cost-push shock process. The model is simply the textbook New-Keynesian model with an extra equation for the price of housing. Note that it still has to be closed with an equation describing the conduct of monetary policy, such as an interest rate rule. Note that asset holdings $h_{t}$ are known to be constant in equilibrium. As a result, $h_{t}$ does not even enter the rational expectations equilibrium conditions.

An important special case of the model obtains when prices are fully flexible and there are no costpush shocks $\left(\xi=0\right.$ and $\left.\eta_{t}=0\right)$. In this case, the allocation in the rational expectations equilibrium is first-best efficient everywhere. Output and the real interest rate are independent of the conduct of monetary policy and are given by:

$$
\begin{aligned}
y_{t}^{n, R E} & =\frac{\phi+1}{\phi+1-\alpha(1-\gamma)} a_{t} \\
r_{t}^{n, R E} & =-\frac{\gamma(\phi+1)}{\phi+1-\alpha(1-\gamma)}\left(1-\rho_{a}\right) a_{t} .
\end{aligned}
$$

These quantities are also called the natural level of output and the natural real rate, respectively.

As is well known, the equilibrium with sticky prices can be expressed in terms of the deviation from this efficient equilibrium. To this end, denote the output gap by $\hat{y}_{t}=y_{t}-y_{t}^{n, R E}$. The sticky price equilibrium can be summarized with the standard two equations:

$$
\begin{aligned}
\pi_{t} & =\beta \mathbb{E}_{t} \pi_{t+1}+\kappa \hat{y}_{t}+\eta_{t} \\
\mathbb{E}_{t} \hat{y}_{t+1}-\hat{y}_{t} & =\frac{1}{\gamma}\left(i_{t}-\mathbb{E}_{t} \pi_{t+1}-r_{t}^{n, R E}\right) .
\end{aligned}
$$


where $\kappa=(1-\xi)(1-\beta \xi)(1+\phi-\alpha+\alpha \gamma) / \xi \alpha$. These equations are the standard New-Keynesian Phillips curve and the IS equation.

\subsection{Learning equilibrium}

In order to solve the learning equilibrium, we have to proceed in two steps. The first is to solve for the agents' policy functions given their beliefs $\mathcal{P}$; the second is to impose market clearing in the asset market to back out the equilibrium asset price.

It is easy to verify that the equilibrium under learning has the same non-stochastic steady state as the rational expectations equilibrium, and we take this as our linearization point. The expectations of agents as well as their optimal choices under the subjective measure $\mathcal{P}$ are expressed as the solution to a "perceived law of motion" (PLM) that, in its linearized form, consists of the following equations:

$$
\begin{aligned}
y_{t} & =a_{t}+\alpha n_{t} \\
\pi_{t} & =\beta \mathbb{E}_{t}^{\mathcal{P}} \pi_{t+1}+\frac{(1-\xi)(1-\beta \xi)}{\xi}\left(w_{t}-a_{t}+(1-\alpha) n_{t}\right)+\eta_{t} \\
w_{t} & =\gamma c_{t}+\phi n_{t} \\
i_{t} & =\gamma\left(\mathbb{E}_{t}^{\mathcal{P}} c_{t+1}-c_{t}\right)+\mathbb{E}_{t}^{\mathcal{P}} \pi_{t+1} \\
q_{t} & =\gamma c_{t}-(1-\beta) \theta h_{t}-\beta \gamma \mathbb{E}_{t}^{\mathcal{P}} c_{t+1}+\beta \mathbb{E}_{t}^{\mathcal{P}} q_{t+1} \\
c_{t} & =y_{t}-\frac{\bar{Q} \bar{H}}{\bar{Y}}\left(h_{t}-h_{t-1}\right) \\
q_{t} & =q_{t-1}+\hat{\mu}_{t-1}+z_{t} \\
\hat{\mu}_{t} & =\rho_{\mu} \hat{\mu}_{t-1}+g z_{t}
\end{aligned}
$$

This system can be solved as if it were a rational expectations model. However, under $\mathcal{P}$, there is an additional shock, the asset price forecast error $z_{t}$, that is absent under rational expectations. This shock will be predictable in equilibrium, but under under $\mathcal{P}$ agents believe it to be unforecastable. The first stage of the solution has to take this into account. Just as under rational expectations, one still needs to add an equation describing the conduct of monetary policy, such as an interest rate rule, for the above system to be fully determined.

Having solved for expectations and optimal choices given $\mathcal{P}$, the equilibrium under learning (also called "actual law of motion" or ALM) is then found by imposing market clearing in the market for housing. This condition simply reads

$$
h_{t}=0
$$


This equation implicitly defines the equilibrium realizations of $z_{t}$. Contrary to agents' beliefs, this forecast error is not an exogenous shock in equilibrium, but an endogenous variable. It is precisely in this sense that expectations are not rational in this model.

\subsubsection{Flexible price PLM}

As before, we first describe the flexible price equilibrium $\left(\xi=0\right.$ and $\left.\eta_{t}=0\right)$. We find the flex-price PLM by solving (23)-(30) under subjective beliefs $\mathcal{P}$. The learning model has two additional state variables compared to its rational expectations counterpart, $q_{t}$ and $\hat{\mu}_{t-1}$. We guess and verify that the asset demand function has the following form:

$$
h_{t}^{n, P L M}=k_{a} a_{t}+k_{h} h_{t-1}^{n, P L M}-k_{q} q_{t}+k_{\mu} \hat{\mu}_{t-1}
$$

where the coefficients satisfy $k_{h} \in(0,1), k_{a}, k_{q}, k_{\mu}>0$. Exact expressions can be found in the appendix. Asset demand under learning is increasing in productivity, decreasing in the asset price, and increasing in expectations of future asset price growth.

We can also solve for the values of output and the real interest rate under flexible prices. Under subjective expectations, these are functions of the fundamental, last period's asset holdings, the asset price which is perceived as exogenous, and price growth expectations. Below, we write output and the real rate in deviation from their rational expectations counterpart: ${ }^{6}$

$$
\begin{aligned}
y_{t}^{n, P L M} & =y_{t}^{n, R E}+\frac{\alpha \gamma \kappa_{1}}{1+\phi-\alpha}\left(k_{a} a_{t}-\left(1-k_{h}\right) h_{t-1}^{n, P L M}-k_{q} q_{t}+k_{\mu} \hat{\mu}_{t-1}\right) \\
r_{t}^{n, P L M} & =r_{t}^{n, R E}+\gamma \kappa_{1}\left(k_{a}\left(2-\rho_{a}-k_{h}\right) a_{t}-\left(1-\kappa_{h}\right)^{2} h_{t-1}^{n, P L M}-k_{q}\left(1-k_{h}\right) q_{t}\right) \\
& +\gamma \kappa_{1}\left(\left(2-\rho_{\mu}-k_{h}\right) k_{\mu}+k_{q}\right) \hat{\mu}_{t-1} .
\end{aligned}
$$

where the constant $\kappa_{1}$ is

$$
\kappa_{1}=\frac{1+\phi-\alpha}{1+\phi-\alpha(1-\gamma)} \frac{\bar{Q} \bar{H}}{\bar{Y}}>0
$$

This natural rate is increasing in the price growth belief $\hat{\mu}_{t-1}$. Agents' subjective expectations about output under flexible prices are affected by the choice of asset holdings (which are not constant in agents' minds). An increase in expected asset price growth will increase asset demand, and households

\footnotetext{
${ }^{6}$ Since the PLM includes asset holdings $h_{t}$ as an endogenous state variable, there are two possible definitions of a natural real rate and natural level of output (Neiss and Nelson, 2003; Woodford, 2003). One can either define them as conditional on the actual level of asset holdings $h_{t-1}$ under sticky prices, or as conditional on the level of asset prices $h_{t-1}^{n, P L M}$ that would obtain had prices been flexible in the past as well, given the history of exogenous shocks. Here, we opt for the latter definition.
} 
will increase their labor supply in order to finance their purchase of the asset, thereby increasing the level of output.

The natural real rate under subjective expectations can be understood by the arbitrage relationship between the return on the durable asset and the return on bonds. Combining the two asset pricing equations (26) and (27), we obtain:

$$
r_{t}^{n, P L M}=\frac{1-\beta}{\beta}\left(\gamma c_{t}-\theta h_{t}-q_{t}\right)+\mathbb{E}_{t}^{\mathcal{P}} q_{t+1}-q_{t}
$$

The expected return on the two assets has to be equal up to first order. An increase in expected durable asset price growth $\hat{\mu}_{t-1}=\mathbb{E}_{t}^{\mathcal{P}} q_{t+1}-q_{t}$ increases the expected return to the durable asset, and the real interest rate on bonds therefore has to rise as well.

\subsubsection{Flexible price ALM}

To find the flex-price equilibrium under learning, i.e. the actual law of motion, one has to impose $h_{t}=0$. From the housing demand function (32), one can then immediately solve for the equilibrium asset price and the realization of the subjective forecast error:

$$
\begin{aligned}
0 & =k_{a} a_{t}-k_{q} q_{t}+k_{\mu} \hat{\mu}_{t-1} \\
\Leftrightarrow q_{t} & =\frac{k_{a} a_{t}+k_{\mu} \hat{\mu}_{t-1}}{k_{q}} .
\end{aligned}
$$

That is, the equilibrium asset price is increasing in both productivity and house price growth expectations. This is intuitive. The demand function (32) is downward-sloping, and so an increase in demand due to either higher productivity (i.e. higher income) or higher expected capital gains has to be met with an increase in the price to bring about equilibrium in the asset market.

It becomes clear that the forecast error $z_{t}$ is every

thing but unforecastable:

$$
z_{t}=\frac{1}{k_{q}} k_{a} a_{t}-q_{t-1}+\left(\frac{k_{\mu}}{k_{q}}-1\right) \hat{\mu}_{t-1} .
$$

This is precisely the way in which rational expectations break in this model. If agents had the correct belief about $z_{t}$, then owing to their conditionally-model consistent expectations, their beliefs would be correct and their expectations would be rational.

Substituting the equilibrium price (35) into Equations (33) and (34), we obtain the realized level of 
output and the real rate under flexible prices:

$$
\begin{aligned}
& y_{t}^{n, A L M}=y_{t}^{n, R E} \\
& r_{t}^{n, A L M}=r_{t}^{n, R E}+\gamma \kappa_{1}\left(\left(1-\rho_{a}\right) k_{a} a_{t}+\left(\left(1-\rho_{\mu}\right) k_{\mu}+k_{q}\right) \hat{\mu}_{t-1}\right) .
\end{aligned}
$$

Under learning and flexible prices, the equilibrium level of output is the same as under rational expectations. This coincidence arises because, under flexible prices, output is determined entirely by intratemporal conditions that are independent of expectations. Nonetheless, the real interest rate does depend on expectations, and its natural level under learning is therefore different from rational expectations. In particular, it is increasing in subjectively expected house price growth.

\subsubsection{Sticky prices}

Just as under rational expectations, the sticky price equilibrium under learning can be expressed in deviation from the flexible price allocation, which greatly helps our analysis. One only has to be careful in keeping apart the flexible price allocations under the PLM and the ALM. We will use tildes for the former and hats for the latter: That is, $\tilde{h}_{t}=h_{t}-h_{t}^{n, P L M}$ denotes the difference of asset holdings from their flex-price level under the PLM, while the difference with the ALM flex price level is denoted $\hat{h}_{t}=h_{t}-h_{t}^{n, A L M}$. The same notation applies to consumption and output. Then the sticky price equilibrium in the PLM can be summarized with three equations:

$$
\begin{aligned}
& \pi_{t}=\beta \mathbb{E}_{t}^{\mathcal{P}} \pi_{t+1}+\kappa\left(\tilde{c}_{t}+\kappa_{1} \Delta \tilde{h}_{t}\right)+\eta_{t} \\
& \tilde{c}_{t}=\mathbb{E}_{t}^{\mathcal{P}} \tilde{c}_{t+1}-\frac{1}{\gamma}\left(i_{t}-\mathbb{E}_{t}^{\mathcal{P}} \pi_{t+1}-r_{t}^{n, P L M}\right) \\
& \tilde{h}_{t}=\frac{\gamma}{\theta(1-\beta)}\left(\tilde{c}_{t}-\beta \mathbb{E}_{t}^{\mathcal{P}} \tilde{c}_{t+1}\right)
\end{aligned}
$$

The first equation is the familiar Phillips curve, but where the output gap is replaced by the consumption gap, augmented by asset purchases $\Delta \tilde{h}_{t}{ }^{7}$ The intuition is that asset purchases are financed by an increase in labor supply, which drives down firms' marginal cost of production and therefore reduces inflation. The second equation is the familar IS equation, where again the output gap is replaced by the consumption gap since the two are not equal under agents' subjective expectations. The third equation is the Euler equation for housing demand, rewritten in gap form.

Notice that the asset price $q_{t}$ itself does not appear in the Euler equation for asset holdings in gap

\footnotetext{
${ }^{7}$ Even though in equilibrium (in the ALM) there can be no housing purchases as the supply of housing is fixed, one cannot simply set $\Delta h_{t}=0$ to compute the equilibrium, since agents are not aware of this restriction.
} 
form. Agents perceive it to be an exogenous process, and therefore to be independent of the degree of price stickiness. It therefore drops out of the gap between flexible and sticky prices, and what is left are those variations in asset demand that are due to variations in the household's discount factor. The asset price still implicitly enters equation (40) through the natural rate $r_{t}^{n, P L M}$.

To find the actual law of motion under sticky prices, one imposes $h_{t}=h_{t}^{n, P L M}+\tilde{h}_{t}=0$ and solves for $q_{t}$. The equilibrium depends crucially on the behavior of the nominal interest rate $i_{t}$, which we have not specified yet.

\subsection{Numerical illustration}

We illustrate the properties of the learning model using a simple calibration in which we interpret the durable asset as housing. We set the labor share in output equal to $\alpha=0.7$ and the discount factor $\beta$ equal to 0.995 . The coefficient of relative risk aversion is set to $\gamma=1.39$ (Gandelman and Hernández-Murillo, 2014) and the inverse Frisch elasticity of labor supply is set to $\phi=0.33$. The utility scaling parameter $\chi$ is set to 0.01005 in order to achieve a steady state ratio of asset wealth to output of $Q H / Y=2.01$, which corresponds to the US ratio of real estate holdings over GDP in 2016. The parameter governing the price elasticity of demand for consumption varieties is set to $\sigma=6$ as in Christiano et al. (2010), while price stickiness is set to the standard value $\kappa=0.75$. We follow Billi (2017) and set the autocorrelation of both the technology and cost-push shocks to 0.8. Finally, we calibrate the remaining four parameters $\left(\sigma_{A}, \sigma_{\tau}, \theta, g\right)$ to jointly match the volatilities of output growth $\sigma\left(\Delta Y_{t}\right)=0.64 \%$, inflation $\sigma\left(\pi_{t}\right)=0.82 \%$, house price growth $\sigma\left(\Delta Q_{t}\right)=1.51 \%$ and real wage growth $\sigma\left(\Delta w_{t}\right)=0.10 \%$. The resulting parameter values are $\sigma_{A}=0.83 \%, \sigma_{p}=0.75 \%, \theta=0.0068$ and $g=0.0041$.

We first document the effect of learning under flexible prices. Here, learning has no effect on equilibrium allocations relative to rational expectations, but manifests itself only in the realized asset price and interest rate process. Figure 2 plots the response of asset prices $Q_{t}$ and the real interest rate $i_{t}$ to a technology shock $\epsilon_{A}$ under rational expectations and learning. The effect of learning on $Q_{t}$ is typical for self-referential asset price learning models. Initially, the asset price $Q_{t}$ rises on impact because higher wage wage income raises asset demand, as under rational expectations. But the initial increase now causes a subsequent revision in beliefs $\hat{\mu}_{t}$ through the learning mechanism. The household believes that the shock has some long-run impact on house price growth and responds by increasing its demand for housing above the rational expectations demand. This response drives a further increase in $Q_{t}$ in the next period and the shock continues to propagate through belief updating thereafter. At 
some point, expected price growth has risen so much that it outstrips realized price growth. At this point, beliefs $\hat{\mu}_{t}$ decrease, bringing about a reduction in housing demand and therefore in equilibrium house prices, so that the process eventually reverts back to steady state.

The differing response of the interest rate between the learning and rational expectations environments directly shows the effect of expected asset price growth on the natural rate of interest. Even though the impulse response of realized consumption is exactly identical under learning and rational expectations, what matters for the interest rate is expected consumption growth. Under learning, increases in expected asset price growth in the periods following the shock also increase expected consumption growth, as agents anticipate to sell some of their asset holdings in the future to profit from the capital gains. Higher expected consumption growth implies a higher real rate of interest under the PLM than under rational expectations.

Figure 2: Effect of learning under flexible prices.
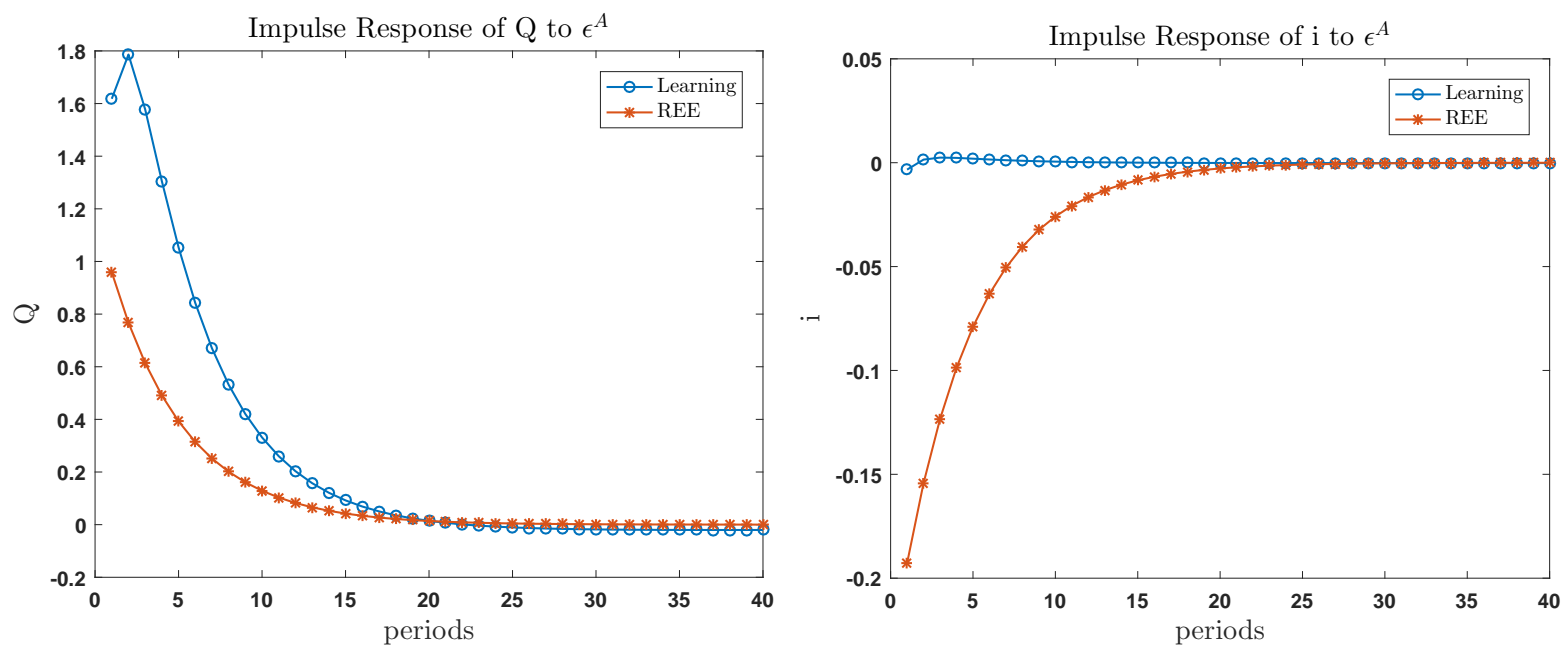

Note: Response to a one standard deviation positive technology shock $\varepsilon_{A t}$. Log percentage points. Flexible prices and zero inflation.

Figure 3 plots the response of $Q_{t}$ and $i_{t}$ to a technology shock $\epsilon_{A}$ under learning and flexible prices for different values of the gain parameter, $g$. A larger learning gain implies that expectations of future asset price growth respond more strongly to shocks, causing larger equilibrium price fluctuations in turn. For a gain close to zero, equilibrium house prices are very close to their rational expectations counterpart. The response of the interest rate, however, remains very different from rational expectations. As the learning gain increases, the asset price as well as the interest rate become more volatile. 
Figure 3: Role of the learning gain $g$, flexible prices.
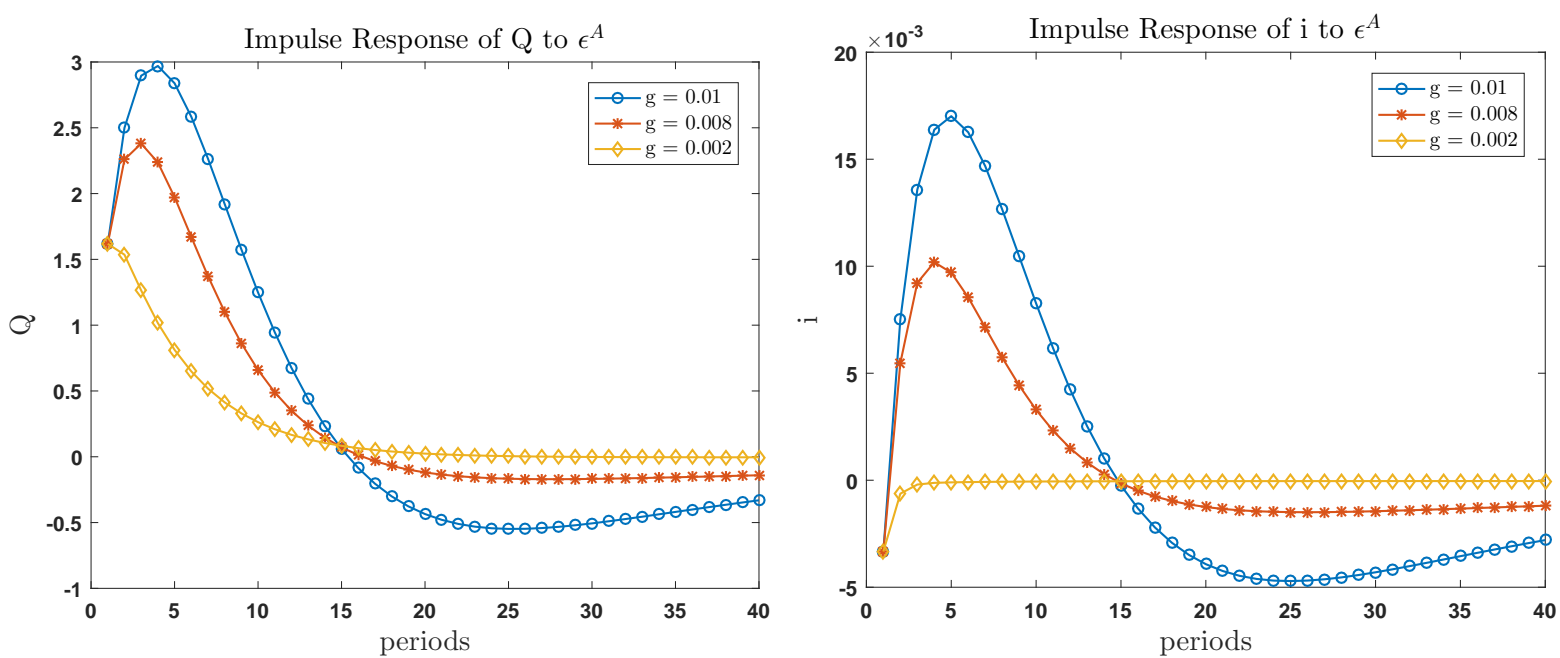

Note: Response to a one standard deviation positive technology shock $\varepsilon_{A t}$. Log percentage points. Flexible prices and zero inflation.

\section{Optimal Policy}

\subsection{Welfare functions}

We provide second-order approximations to the expected discounted sum of utility in our model. Under learning, an important distinction has to be made whether welfare is evaluated under the subjective law of motion (in which asset supply is variable and prices are a random walk) or under the actual law of motion (in which asset supply is fixed and prices are functions of the model fundamentals).

If we evaluate welfare under the actual law of motion, then welfare can be approximated by $-\sum_{t=0}^{\infty} \mathbb{E}_{0} \mathcal{L}_{t}$ up to second order, terms independent of policy, and a multiplying positive constant. The period loss function is given by

$$
\mathcal{L}_{t}=\lambda \pi_{t}^{2}+\hat{y}_{t}^{2}
$$

where $\lambda=2 \sigma \alpha \xi(1-\xi)^{-1}(1-\beta \xi)^{-1}(1+\phi-\alpha(1-\gamma))^{-1}$ and $\hat{y}_{t}=y_{t}-y_{t}^{n, R E}$ is the deviation of output from its flex-price level. This loss function is identical to that of the standard rational expectations New Keynesian model. It penalizes deviations of inflation from zero as well as deviations of output from the natural rate of output under rational expectations (19). This natural rate of output is first-best efficient under the ALM.

By contrast, the welfare function under the PLM takes a quite different form. Welfare is approxi- 
mated by $-\sum_{t=0}^{\infty} \beta^{t} \mathbb{E}_{0}^{\mathcal{P}} \mathcal{L}_{t}^{P L M}$, where the period loss function is given by

$$
\begin{aligned}
\mathcal{L}_{t}^{P L M} & =\lambda \pi_{t}^{2}+\tilde{c}_{t}^{2} \\
& +\frac{1-\alpha+\phi}{1+\phi-\alpha(1-\gamma)}\left(\frac{\bar{Q} \bar{H}}{\bar{Y}} \Delta \tilde{h}_{t}\right)^{2}+2 \tilde{c}_{t}\left(\frac{\bar{Q} \bar{H}}{\bar{Y}} \Delta \tilde{h}_{t}\right) \\
& -\frac{(1-\beta) \theta \alpha}{1+\phi-\alpha(1-\gamma)} \frac{\bar{Q} \bar{H}}{\bar{Y}} \tilde{h}_{t}^{2} .
\end{aligned}
$$

where $\tilde{c}_{t}$ and $\tilde{h}_{t}$ are the deviations of consumption and asset holdings from their PLM-flexible price levels. Here, the period loss takes the form of deviations from the flexible price allocations under the PLM, and also includes terms for asset holdings. Those terms do not appear in the ALM loss function because asset holdings are constant in equilibrium.

\subsection{Optimal policy without cost-push shocks}

We now solve for the optimal monetary policy, first under the assumption that there are no cost-push shocks. For exposition, we start by reviewing the optimal policy under rational expectations. As the flexible price equilibrium under rational expectations is first-best efficient, monetary policy is optimal if it manages to replicate the flexible price allocation in the presence of nominal rigidities. This amounts to closing the output gap and completely stabilizing the price level at the same time, as can be seen from the loss function (41). Without cost-push shocks, the "divine coincidence" holds and complete stabilization is achievable. The optimal policy implements

$$
\pi_{t}=0
$$

From the Phillips curve (21), it immediately follows that $\hat{y}_{t}=0$. The optimal policy can be implemented with the following rule:

$$
i_{t}=r_{t}^{n, R E}+\phi_{\pi} \pi_{t}
$$

where $\phi_{\pi}$ can be any number satisfying the Taylor principle $\phi_{\pi}>1$. The interest rate has to track the natural real rate and react more than one-for-one to inflation, i.e. satisfy the Taylor principle.

Under learning, the question is which welfare criterion to use. Should the central bank aim to maximize agents' subjectively expected discounted utility and minimize the loss function 42 under the PLM? Or should it aim to maximize average realized utility and minimize the loss function 41 under the ALM? Fortunately, both welfare criteria prescribe the same optimal outcome here. 
Proposition 1. The optimal monetary policy under learning implements $\pi_{t}=0$ and $y_{t}=y_{t}^{n, R E}$, regardless of whether welfare is evaluated under the ALM or the PLM. The optimal policy can be implemented with the rule $i_{t}=r_{t}^{n, P L M}+\phi_{\pi} \pi_{t}$, where $\phi_{\pi}>1$.

Proof. Suppose that the central bank implemented $\pi_{t}=0$. The PLM Phillips curve (38) then reduces to the relationship

$$
\tilde{y}_{t}=\frac{\gamma \alpha}{1+\phi-\alpha(1-\gamma)} \frac{\bar{Q} \bar{H}}{\bar{Y}} \Delta \tilde{h}_{t}
$$

Substituting into the housing demand equation (40), we obtain a second-order difference equation of the form

$$
(1-\beta) \frac{\theta}{\gamma} \tilde{h}_{t}=-\kappa_{1}\left(\Delta \tilde{h}_{t}-\beta \mathbb{E}_{t}^{\mathcal{P}} \Delta \tilde{h}_{t+1}\right)
$$

It is easily verified that the only solution to this equation is $\tilde{h}_{t}=0$. But this implies that we implement the flexible price allocation. From the subjective perspective of agents, the flexible price allocation is first-best efficient. Therefore, strict inflation targeting is optimal from the subjective perspective of agents. Moreover, the actual equilibrium in this economy has $\pi_{t}=0$ and $y_{t}=y_{t}^{n, R E}$, as was shown in the last section. This allocation is also first-best efficient under model-consistent expectations, and therefore optimal under model-consistent expectations as well.

It might seem at first that the presence of learning does not alter the prescriptions of optimal policy because the target criterion strict inflation targeting is unchanged. But the implementation of this target requires a different reaction function under learning. The nominal interest rate has to track the natural real interest rate $r_{t}^{n, P L M}$ as agents perceive it under subjective expectations. This natural rate is very different from the one under rational expectations. Whereas $r_{t}^{n, R E}$ is a function of productivity $a_{t}$ only, $r_{t}^{n, P L M}$ depends additionally on beliefs $\hat{\mu}_{t}$, prices $q_{t}$ and the asset holdings $h_{t-1}$. In particular, the real rate rises when expected asset price growth $\hat{\mu}_{t}$ increases. In equilibrium, the asset price $q_{t}$ depend positively on expected price growth, and it is in this sense that the optimal monetary policy leans against the wind: In times of high prices, the interest rate has to be high to track the perceived natural real rate.

The equilibrium realization of the nominal rate under the optimal policy is the expression $r_{t}^{n, A L M}$ derived in (37). However, an instrument rule that prescribes $i_{t}=r_{t}^{n, A L M}+\phi_{\pi} \pi_{t}$ would fail to implement the optimal policy. The equilibrium natural rate $r_{t}^{n, A L M}$ only coincides with the perceived natural rate when $h_{t}=0$. While this must be the case in equilibrium, agents under $\mathcal{P}$ contemplate other possible realizations of the house price for which they plan on choosing $h_{t} \neq 0$. These off-equilibrium states of 
the world enter into agents' expectations of future marginal costs. Therefore, the central bank must promise to stabilize inflation even in these off-equilibrium states. Tracking only the equilibrium natural rate is insufficient: It must track the perceived natural rate.

As an illustration, Figure 4 shows impulse responses for the learning model with three interest rate equations:

$$
\begin{aligned}
& i_{t}=r_{t}^{n, P L M}+1.05 \pi_{t} \\
& i_{t}=r_{t}^{n, A L M}+1.05 \pi_{t} \\
& i_{t}=r_{s s}+1.5 \pi_{t}+0.125 \hat{y}_{t} .
\end{aligned}
$$

The first equation (47) implements strict inflation targeting as per Proposition 1 . The only difference of the second equation (48) is that the monetary authority reacts to the equilibrium process of the natural rate instead of the perceived process. Figure 4 shows how using the ALM natural rate of interest in the the policy rule does not yield a zero inflation outcome. As discussed in the last section, the central bank must promise to stabilize inflation even in those states that are never reached in equilibrium - that is, when the housing market doesn`t clear-but contemplated by agents under their subjective expectations. Using the ALM natural rate in the policy rule fails to do so. Due do their beliefs about the process governing $Q_{t}$, agents under the PLM do not account for the effect of the technology shock on future asset price growth. Consequently, the initial response of consumption is smaller than under rational expectations. From the standpoint of an agent under the flex price ALM on the other hand, the technology shock has an anticipated positive impact on the path of $Q_{t}$ due to expected asset demand. As a result, the initial consumption response and subsequent consumption decline will be greater. The ALM natural rate of interest declines more upon the impact of the shock than does the PLM natural rate of interest. When a monetary authority uses the ALM natural rate in its policy rule as in (48), then, the nominal interest does not increase sufficiently to prevent an inflationary response.

Finally, the third equation is a standard Taylor rule. Figure 4 shows that this rule performs somewhat better in terms of outcomes, but is still far from the optimal policy. It is worth notint that the nominal interest rate is more volatile under the Taylor rule than under the optimal rule (47), which reacts to asset prices. The reason is of course that the stabilization benefits of reacting to asset prices make equilibrium nominal rates more stable as well. 
Figure 4: Optimal policy and alternatives after a technology shock.
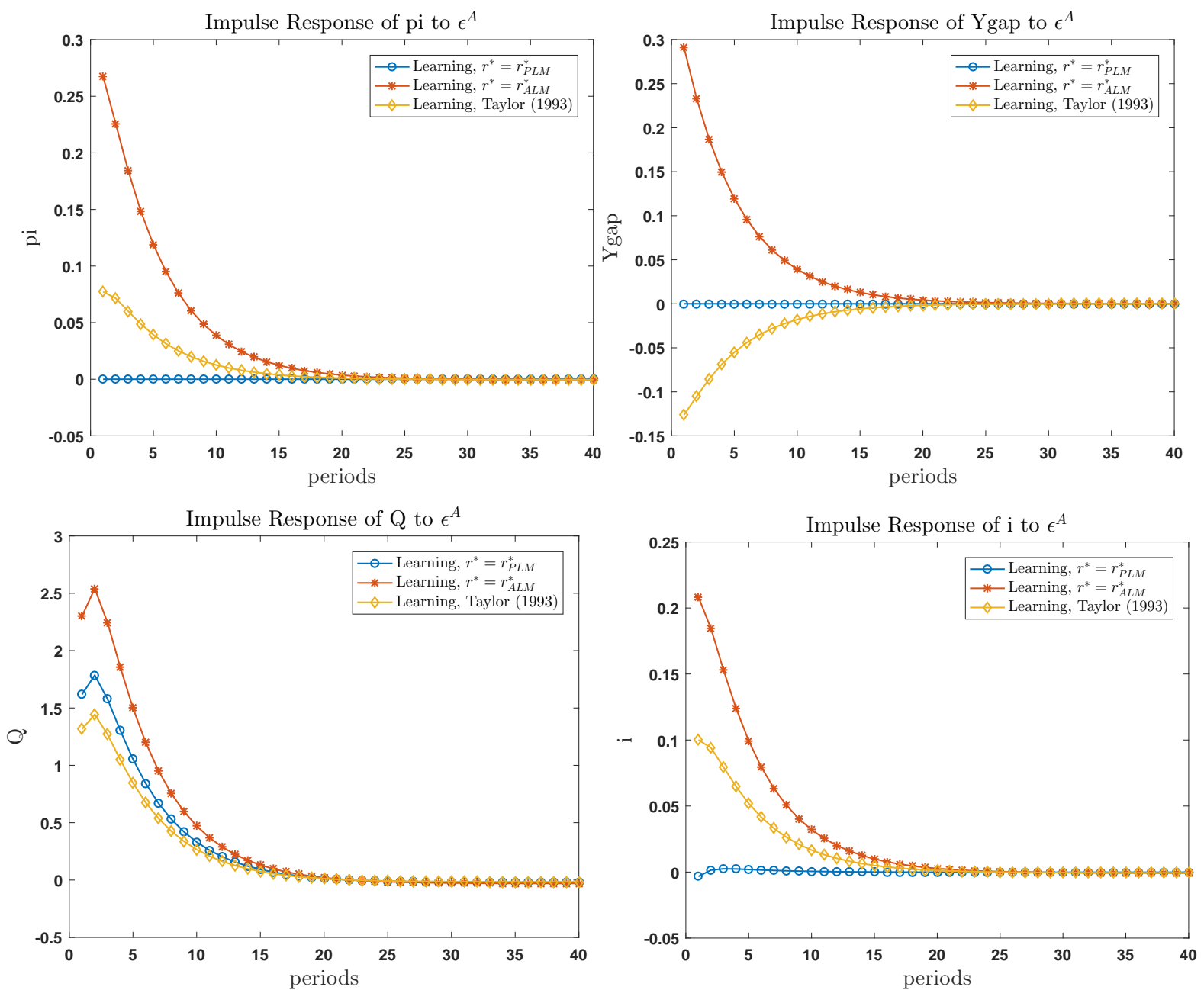

Note: Response to a unit standard deviation positive technology shock $\varepsilon_{A t}$ under sticky prices. Log percentage points. The interest rate rules used are given in Equations (47)-(49).

\subsection{Optimal policy with cost-push shocks}

The presence of cost-push shocks breaks the so-called "divine coincidence" under rational expectations, so that the first-best allocation is not feasible. Here, we will show first that in principle, a sophisticated policymaker with knowledge of the precise nature of the belief distortions under learning can restore the first-best outcome by twisting private sector expectations to its advantage through a highly non-linear policy. This is clearly the optimal policy, but we do not see it as relevant in practice. Instead, we restrict the set of admissible policies to a known class of linear targeting rules and show that it is possible to replicate the allocations of the RE-optimal policy under discretion and commitment. As in the case without cost-push shocks, implementing these policies requires the nominal interest rate to track the natural rate of interest under the PLM, which is increasing in asset price expectations.

Proposition 2. With cost-push shocks and learning, it is possible to implement the first-best allocation 
with the targeting rule $\pi_{t}=-\left(\beta \rho_{\eta}\right)^{-1} \eta_{t}+b_{t} z_{t}$, where $b_{t}$ is a non-linear state-dependent coefficient.

Proof. See the appendix.

Clearly, this is the optimal policy with cost-push shocks, but we see this result as somewhat problematic. First, the policy implies a high degree of belief manipulation by the central bank that is particularly vulnerable to the Lucas critique. This problem was anticipated by Woodford (2010) who wrote that one "might even conclude that the optimal policy under learning achieves an outcome better than any possible rational-expectations equilibrium, by inducing systematic forecasting errors of a kind that happen to serve the central bank's stabilization objectives". Moreover, it is difficult to see how such a highly non-linear policy would be credible in the first place.

Here, we will alleviate this problem by restricting the set of admissible policies to those that are familiar from the New-Keynesian literature, and that do not rely on a systematic exploitation of agents' systematic forecast errors. Under rational expectations, it is well known that the optimal discretionary policy seeking to minimize the loss function (41) satisfies (e.g. Woodford, 2003):

$$
\begin{aligned}
\pi_{t} & =\zeta \eta_{t} \\
\left(y_{t}-y_{t}^{n, R E}\right) & =-\frac{1-\zeta(1-\beta \rho)}{\kappa \zeta} \pi_{t}
\end{aligned}
$$

where the sensitivity $\zeta$ of inflation to the cost-push shock is given by $\zeta_{d i s c}=\left(1-\beta \rho+\lambda \kappa^{2}\right)^{-1}$. It is also possible to solve for the weight $\zeta^{*}$ that minimizes the loss function (41) within the class of policies implementing $\pi_{t}=\zeta \eta_{t}$. This optimal weight is given by $\zeta^{*}=\left(1-\beta \rho+\lambda \kappa^{2} /(1-\beta \rho)\right)^{-1}$. The interest rate rule that implements this policy is given by

$$
i_{t}=r_{t}^{n, R E}+\left(\rho+\gamma(1-\rho) \frac{1-\zeta(1-\beta \rho)}{\kappa}\right) \frac{1}{\zeta} \pi_{t}
$$

Under learning, we obtain the following result:

Proposition 3. The allocation in (50)-(51) is attainable under learning for any value of $\zeta$ in the ALM. The nominal interest rate that implements the allocation follows

$$
\begin{aligned}
i_{t} & =r_{t}^{n, P L M}+a \frac{1+\phi-\alpha}{\kappa_{1} \alpha} \tilde{y}_{t} \\
& +\left(\rho+\gamma(1-\rho) \frac{1-\zeta(1-\beta \rho)}{\kappa}\left(\left(1+\frac{\kappa_{1} \gamma(1-\beta \rho)}{\theta(1-\beta)+\gamma \beta a}\right)^{-1}+a \frac{1+\phi-\alpha}{\kappa_{1} \alpha \kappa \gamma(1-\rho)}\right)\right) \frac{1}{\zeta} \pi_{t} .
\end{aligned}
$$

where the coefficient $a \in(0,1)$ is defined in the appendix. 
In particular, the optimal discretionary policy outcome under RE is attainable under learning with $\zeta=\zeta_{\text {disc }}$. Moreover, within the class of policies of the form (50), the weight $\zeta=\zeta^{*}$ maximizes ALM welfare under learning. The expression for the nominal interest rate shows that the equilibrium interest rate path depends on inflation and the perceived output gap as well as the natural rate. The natural rate is increasing in the level of asset prices as well as the subjective expectation of future asset price growth. Therefore, the nominal interest rate in (88) is effectively reacting to asset prices.

\section{Simple rules}

Implementing optimal policy in the learning environment requires knowledge of the natural rate of interest under the PLM. In particular, it implies that the monetary authority knows the agents' beliefs about $\mu_{t}$, which in part determine $r^{n, P L M}$ in equilibrium. An obvious concern is that beliefs that are subjective and privately held are hard to measure. In this section, we show that incorporating a positive reaction to asset prices into a standard interest rate rule can allow a monetary authority who does not observe beliefs to approximate optimal policy under learning. This result is not a natural consequence of the optimal policy analysis, because simple rules can be quite far from the optimal policy. A reaction to asset prices will tend to be beneficial in a rule if periods of elevated asset prices coincide with excess aggregate demand under that particular rule. For our calibrated model and the standard Taylor rule, that turns out to be the case.

We re-compute the model under the assumption that the monetary authority is following a Taylortype rule of the form:

$$
i_{t}=\rho_{i} i_{t-1}+\left(1-\rho_{i}\right) \cdot\left(r_{s s}+\phi_{\pi} \cdot \pi_{t}+\phi_{y} \cdot \hat{y}_{t}+\phi_{q} \cdot \sum_{s=0}^{\infty} \omega^{s} \Delta \log Q_{t-s}\right)
$$

The rule depends on inflation and the output gap, and has an additional term for asset prices: a moving average of past price changes, with a weight on past observations that decays at the rate $\tilde{\omega} \in(0,1)$. In what follows, we keep the coefficient on inflation at $\phi_{\pi}=1.5$ and find the tuples $\left(\rho_{i}, \phi_{y}, \phi_{q}, \tilde{\omega}\right)$ that minimize either (41) under the equilibrium probability measure, or (42) under the subjective probability measure. $^{8}$ We impose the constraint $0 \leq \tilde{\omega} \leq 0.999$. Table 1 shows the optimized rule coefficients and compares them to the outcome of the optimal target criterion from Section 6.2.

\footnotetext{
${ }^{8}$ If one also optimizes over the coefficient and inflation, then the optimal policy under rational expectations is given by $\phi_{\pi} \rightarrow \infty$ and $\phi_{y} / \phi_{\pi} \rightarrow \zeta>0$ (Boehm and House, 2014). The outcomes of this limit policy are also attainable under learning with a similar policy that also responds infinitely strongly to inflation and the ouput gap. In this section, we rule out infinite rule coefficients by keeping the inflation coefficient fixed, and focus only on the tradeoff of reacting to the output gap and asset prices.
} 
Table 1: Performance of optimized simple rules.

\begin{tabular}{|c|c|c|c|c|c|}
\hline & Rational Expectations & $\sigma\left(\pi_{t}\right)$ & $\sigma\left(\hat{y}_{t}\right)$ & $\sigma\left(\Delta q_{t}\right)$ & $\mathcal{L}$ \\
\hline (1) & $i_{t}=r_{s s}+1.5 \pi_{t}+0.125 \cdot \hat{y}_{t}$ & 0.349 & 0.451 & 0.801 & 3.315 \\
\hline (2) & $\begin{array}{l}i_{t}=\rho_{i}^{*} i_{t-1}+\left(1-\rho_{i}^{*}\right) \cdot\left(r_{s s}+1.5 \pi_{t}+\phi_{y}^{*} \cdot \hat{y}_{t}\right) \\
\quad\left\{\rho_{i}^{*}, \phi_{y}^{*}\right\}=\{0.844,0.331\}\end{array}$ & 0.249 & 0.472 & 0.515 & 1.888 \\
\hline (3) & $\begin{array}{l}\pi_{t}=\zeta^{*} \eta_{t} \\
\zeta^{*}=0.040\end{array}$ & 0.050 & 0.492 & 1.098 & 0.577 \\
\hline & Learning & $\sigma\left(\pi_{t}\right)$ & $\sigma\left(\hat{y}_{t}\right)$ & $\sigma\left(\Delta q_{t}\right)$ & $\mathcal{L}$ \\
\hline (4) & $\begin{array}{l}i_{t}=\rho_{i}^{*} i_{t-1}+\left(1-\rho_{i}^{*}\right) \cdot\left(r_{s s}+1.5 \pi_{t}+\phi_{y}^{*} \cdot \hat{y}_{t}\right) \\
\quad\left\{\rho_{i}^{*}, \phi_{y}^{*}\right\}=\{0,0.041\}\end{array}$ & 0.051 & 0.476 & 1.741 & 0.559 \\
\hline (5) & $\begin{array}{l}\pi_{t}=\zeta^{*} \eta_{t} \\
\zeta^{*}=0.040\end{array}$ & 0.050 & 0.492 & 1.879 & 0.577 \\
\hline (6) & $\begin{array}{l}i_{t}=\rho_{i}^{*} i_{t-1}+\left(1-\rho_{i}^{*}\right) \cdot\left(r_{s s}+1.5 \pi_{t}\right) \\
\quad \rho_{i}^{*}=0\end{array}$ & 0.014 & 0.541 & 1.911 & 0.656 \\
\hline (7) & $\begin{array}{l}\text { BG }(1999) \mathrm{w} / \text { asset price } \\
\quad i_{t}=\rho_{i}^{*} i_{t-1}+\left(1-\rho_{i}^{*}\right) \cdot\left(r_{s s}+1.5 \pi_{t}+\phi_{q}^{*} \cdot \log q_{t-1}\right) \\
\quad\left\{\rho_{i}^{*}, \phi_{q}^{*}\right\}=\left\{0,3.6 \times 10^{-5}\right\}\end{array}$ & 0.013 & 0.541 & 1.912 & 0.656 \\
\hline (8) & $\begin{array}{l}\text { BG }(2001) \mathrm{w} / \text { asset price } \\
\quad i_{t}=\rho_{i}^{*} i_{t-1}+\left(1-\rho_{i}^{*}\right) \cdot\left(r_{s s}+1.5 \pi_{t}+\phi_{q}^{*} \cdot \log q_{t}\right) \\
\quad\left\{\rho_{i}^{*}, \phi_{q}^{*}\right\}=\left\{0,7.5 \times 10^{-4}\right\}\end{array}$ & 0.012 & 0.541 & 1.911 & 0.655 \\
\hline (9) & $\begin{array}{l}i_{t}=\rho_{i}^{*} i_{t-1}+\left(1-\rho_{i}^{*}\right) \cdot\left(r_{s s}+1.5 \pi_{t}+\phi_{q}^{*} \cdot \sum_{s=0}^{\infty} \omega^{* s} \Delta \log Q_{t-s}\right) \\
\quad\left\{\rho_{i}^{*}, \phi_{q}^{*}, \omega^{*}\right\}=\{0,0.010,0.268\}\end{array}$ & 0.025 & 0.531 & 1.792 & 0.645 \\
\hline (10) & $\begin{array}{l}\text { FM }(2007) \mathrm{w} / \text { asset price } \\
\quad i_{t}=\rho_{i}^{*} i_{t-1}+\left(1-\rho_{i}^{*}\right) \cdot\left(r_{s s}+1.5 \pi_{t}+\phi_{y}^{*} \cdot \hat{y}_{t}+\phi_{q}^{*} \cdot \log q_{t}\right) \\
\quad\left\{\rho_{i}^{*}, \phi_{y}^{*}, \phi_{q}^{*}\right\}=\{0.405,0.064,0.012\}\end{array}$ & 0.045 & 0.441 & 1.700 & 0.476 \\
\hline (11) & $\begin{array}{l}i_{t}=\rho_{i}^{*} i_{t-1}+\left(1-\rho_{i}^{*}\right) \cdot\left(r_{s s}+1.5 \pi_{t}+\phi_{y}^{*} \cdot \hat{y}_{t}+\phi_{q}^{*} \cdot \sum_{s=0}^{\infty} \omega^{* s} \Delta \log Q_{t-s}\right) \\
\quad\left\{\rho_{i}^{*}, \phi_{y}^{*}, \phi_{q}^{*}, \omega^{*}\right\}=\{0.408,0.064,0.012,0.999\}\end{array}$ & 0.045 & 0.442 & 1.701 & 0.477 \\
\hline
\end{tabular}


The first three rows show results under rational expectations. Row (1) shows our baseline policy rule while Row (2) shows the optimized values of persistence and the output gap coefficient, holding constant the coefficient on inflation. This rule is more aggressive than the standard Taylor rule and leads to welfare gains from output gap stabilization. Alowing for a non-zero asset price response in the optimization leads to $\phi_{q}=0$ : There is no benefit from leaning against the wind under rational expectations. ${ }^{9}$ Row (3) also shows the outcomes from the optimal target rule derived in Section 6.2. This target rule dramatically improves welfare, mainly by reducing inflation volatility.

Under learning, the picture is quite different. Row (4) repeats the baseline policy rule, with both interest rate persistence $\rho_{i}$ and the output gap response $\phi_{y}$ set to their optimized value. The resulting rule displays zero interest rate persistence and has a less aggresive output gap response than the standard Taylor rule. Nevertheless, inflation volatility is lower than under rational expectations, thereby improving welfare. Row (5) shows the outcomes from the optimal target rule derived in 6.2. As was shown in Section 6.2, the allocations induced by this rule are identical to those in Row (3). Rows (6) (8) show the effect of including the asset price level in a rule that does not have an output response as in Bernanke and Gertler (1999) or Bernanke and Gertler (2001). In each case the optimal asset price response is near-zero, with no gain in welfare. The situation is somewhat different when a weighted average of past asset price growth is included instead (Row (9)). The optimal asset price response is positive, with a slight decrease in output gap volatility driving a 1.7 percent gain in welfare. The gains to reacting to asset prices are more pronounced when an output gap response is included in the simple rule. Row (11) shows the results when the model is simulated under the simple rule specified in (54) with optimized coefficient values. Once again reacting to the asset price is optimal. The optimal coefficient on the output gap is positive, and the optimal $\omega$ is set very close to one. With this value its dynamics are closer to the subjective belief $\hat{\mu}_{t}$, which itself is a moving average of past price changes. The reaction to the asset price stabilizes the output gap and lowers the volatility of asset prices, resulting in a near-15 percent welfare gain. The results are similar when the asset price level is included in the rule instead of the weighted average, as in Faia and Monacelli (2007). It is important to highlight that under learning the simple interest rate rules outperform the optimal target criterion when a reaction to both asset prices and the output gap is present. It is also worth noting that the optimized interest rate rules do not reduce asset price volatility to its level under rational expectations. The reason is of course that asset price volatility does not enter the loss function directly, and so the central bank cares only about the effects of asset price movements on inflation and the output gap.

\footnotetext{
${ }^{9}$ In fact, the optimal coefficient on asset prices would be slightly negative had we not imposed $\phi_{q} \geq 0$.
} 
To get a better idea of the effects of monetary policy reactions to asset prices and the output gap under learning, we compute loss function values as well as the volatilities of inflation, the output gap and asset prices over a range of parameters. We fix the moving average weight to $\tilde{\omega}=0.9$, the interest rate persist to $\rho_{i}=0$, and vary the magnitude of the response coefficients $\phi_{y}$ and $\phi_{q}$ on the output gap and inflation. ${ }^{10}$ Figure 5 contains the results as surface plots.

Figure 5: Loss values and volatilities for different output gap and asset price coefficients.

(a) Inflation volatility.

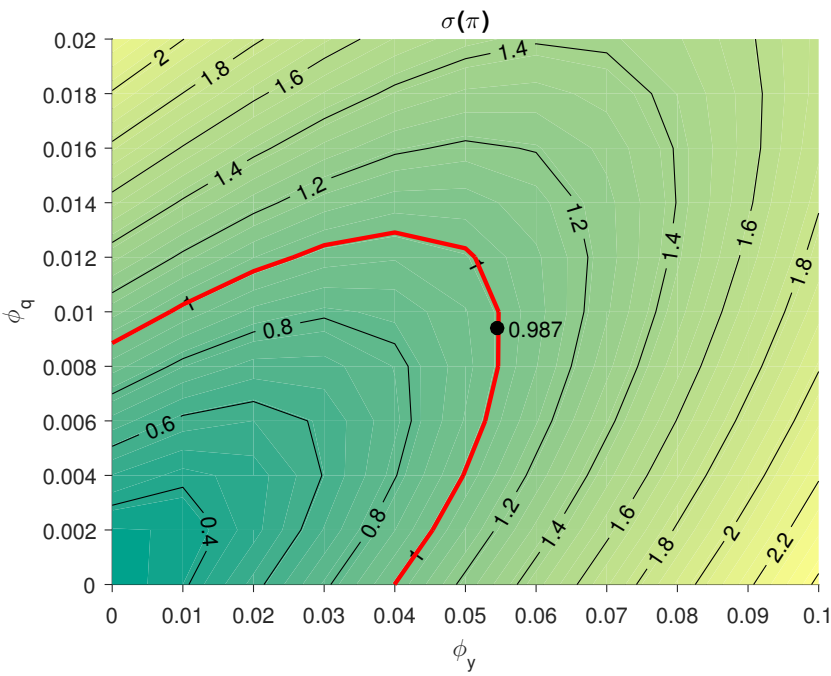

(c) Asset price volatility.

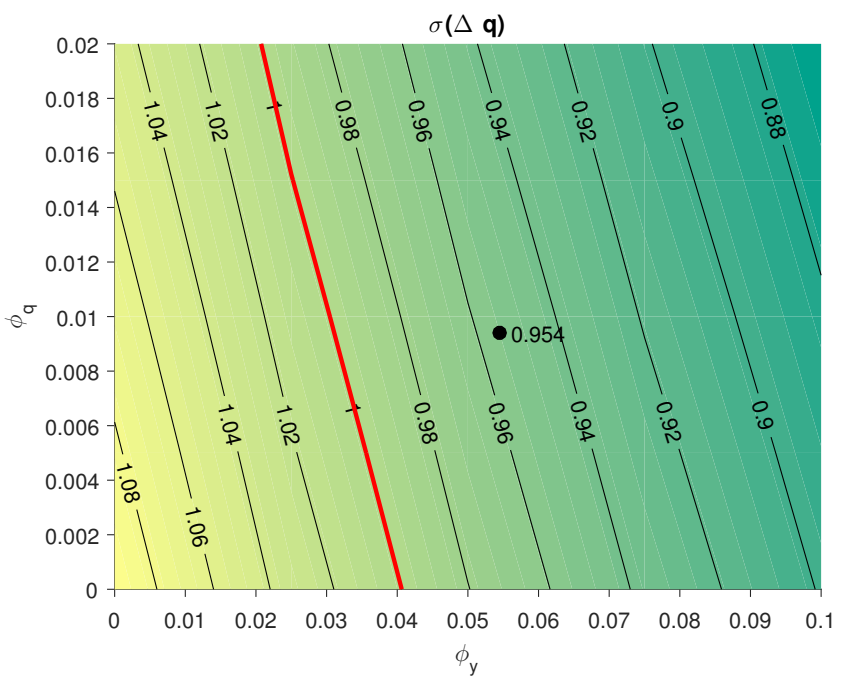

(b) Output gap volatility.

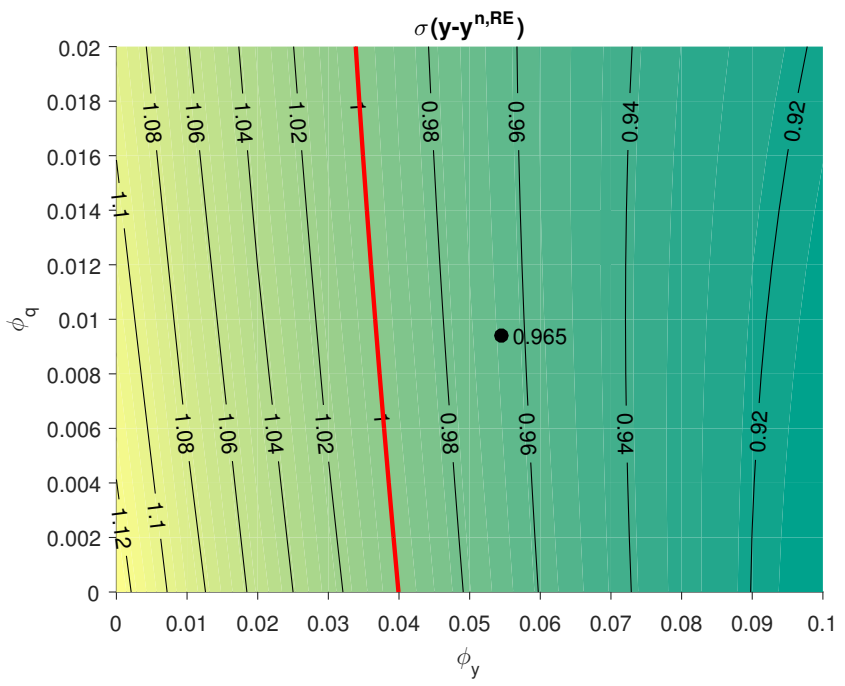

(d) Loss function.

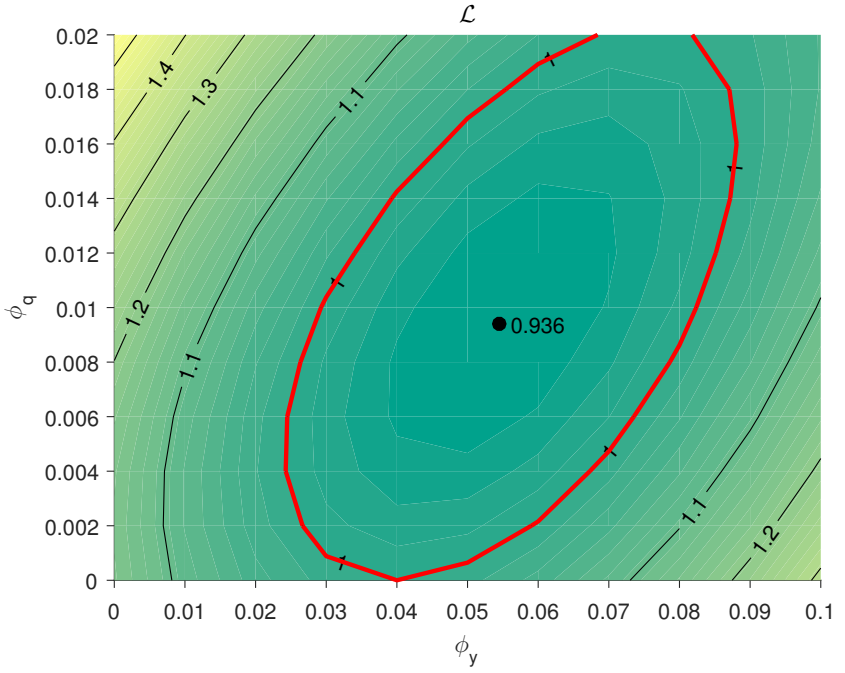

Note: Unconditional standard deviation of inflation $\pi_{t}$, house price growth $\Delta q_{t}$ and output gap $\hat{y}_{t}$ under the ALM, and loss function $\mathcal{L}$, as a function of $\phi_{y}$ and $\phi_{q}$, keeping $\tilde{\omega}=0.9$ throughout. All values are reported relative to the rule in Row (5) of Table 1. Red lines denote contour lines at unity, i.e. the value attained by the optimal coefficient $\phi_{y}$ with $\phi_{q}=0$. Black dots denote the value attained under the unrestricted optimal coefficients, reported in Row (6) of Table 1.

The effect of changes in the output gap coefficient are as expected: They lower the volatility of the output gap itself, but increase the volatility of inflation. This trade-off arises because the model has

\footnotetext{
${ }^{10}$ Our results are qualitatively robust to changes in the moving average weight $\omega$. In particular, a positive reaction to asset prices $\phi_{q}>0$ always reduces asset price volatility.
} 
cost-push shocks in it. A reaction to the output gap also lowers asset price volatility in this model.

But the asset price coefficient also plays an important role. The volatility of asset prices is decreasing in the asset price response $\phi_{q}$. The volatility of the output gap is only little affected by the asset price response, but the volatility of inflation is reduced significantly with $\phi_{q}>0$. Therfore, the loss function is minimized at a strictly interior point at which the central bank reacts to both the output gap and asset price growth.

Importantly, a reaction to asset prices always decreases asset price volatility (regardless of the value of $\tilde{\omega})$. This is in stark contrast to the rational bubbles of Gali $(2014,2017)$. Rational bubbles grow at the rate of interest, and so raising rates when a bubble is growing makes it grow even faster, causing more volatility. By contrast, raising rates in the learning model here has the effect of lowering the house price today: A higher real rate requires a higher expected return on housing. For a given expected capital gain $\hat{\mu}_{t}$, a higher return needs to be brought about by a lower price today. The reduction in the house price today then reduces optimism about future price growth.

\section{Extension: General Asset Price Beliefs}

One might wonder whether our results hinge in any way on our assumption that agents' subjective beliefs about asset prices are given by a simple random walk with drift. In this section, we show that this is not the case. All our results so far extend to a very general form of beliefs about asset prices that encompass extrapolative as well as attenuating beliefs relative to rational expectations, "natural expectations" (Fuster et al., 2012), "diagnostic expectations" (Bordalo et al., 2018) and other forms of non-rational beliefs. The only assumptions we have to retain are that expectations are conditionally model-consistent in the sense of Definition 2, and that the subjective law of motion for asset prices is independent of policy. While this second assumption is admittedly somewhat limiting, an environment in which agents do think that monetary policy can curb asset price booms probably provides an even stronger rationale for reacting to asset prices than what we discuss here.

We replace the subjective law of motion for asset prices in (12)-(13) with a general belief of the form:

$$
q_{t}=A(L) z_{t}+B(L) u_{t}
$$

where $A$ and $B$ are arbitrary lag polynomials. Subjective beliefs can depend in an arbitrary way on the fundamental shocks $u_{t}$ (i.e. productivity and cost-push shocks) as well as a subjective forecast error $z_{t}$. The general formula nests rational expectations, our baseline belief system, and a multitude of other 
forms of subjective beliefs.

Under flexible prices, we can show that the housing demand function in the PLM (i.e. under $\mathcal{P}$ ), which previously was given by (32), is replaced by:

$$
h_{t}^{n, P L M}=k_{a} a_{t}+k_{h} h_{t-1}^{n, P L M}+k_{q} q_{t}+\tilde{k}_{\mu} \sum_{s=0}^{\infty} \tilde{\rho}^{s} \mathbb{E}_{t}^{\mathcal{P}} \Delta q_{t+s+1} .
$$

The coefficients $k_{a}, k_{h}$ and $k_{q}$ are the same as in the original model, and moreover we have $\tilde{k}_{\mu}>0$ and $0<\tilde{\rho}<\beta$.The natural real rate under the PLM has a somewhat more convoluted form, but importantly, it is still increasing in expectations of asset price growth:

$$
\begin{aligned}
r_{t}^{n, P L M} & =r_{t}^{, R E}+\gamma \kappa_{1}\left(k_{a}\left(2-\rho_{a}-k_{h}\right) a_{t}-\left(1-\kappa_{h}\right)^{2} h_{t-1}^{n, P L M}+k_{q}\left(1-k_{h}\right) q_{t}\right) \\
& +\gamma \kappa_{1}\left(\frac{\tilde{k}_{\mu}}{\tilde{\rho}}-k_{q}\right) \mathbb{E}_{t}^{\mathcal{P}} \Delta q_{t+1}+\gamma \kappa_{1} \tilde{k}_{\mu}\left(1-k_{h}-\frac{1-\tilde{\rho}}{\tilde{\rho}}\right) \sum_{s=1}^{\infty} \tilde{\rho}^{s} \mathbb{E}_{t}^{\mathcal{P}} \Delta q_{t+s+1}
\end{aligned}
$$

Moreover, since the asset price $q_{t}$ is independent of policy under the PLM, it drops out of the equations describing the dynamics of the sticky price equilibrium relative to flexible prices. Equations

(38)-(40) continue to hold and the asset price enters only indirectly through the natural real rate $r_{t}^{n, P L M}$, which itself is independent of policy. As a consequence, all our results from Section 6 continue to hold.

\section{Extension: Asset Production}

In the model presented thus far, learning causes distortions only through wealth effects affecting aggregate demand. But one of the main concerns about financial stability in macroeconomics is that overoptimism and -pessimism in financial markets might cause inefficient investment fluctuations. Here, we extend the model to allow for the durable asset to be produced instead of being in fixed supply. In this extension, asset price misalignments do distort investment decisions in addition to aggregate demand, and therefore also distort the flexible price allocation. This fundamentally changes the monetary policy tradeoff.

Relative to the baseline model, we now assume that the stock of the durable asset depreciates at the rate $\delta$. The representative household owns firms that can produce $I_{t}$ durable assets from $K_{t}$ consumption goods. Their production function has decreasing returns to scale:

$$
I_{t}=A_{h} K_{t}^{\omega}
$$


Production takes place within one period. The profits of the investment firms are:

$$
\Pi_{t}=Q_{t} I_{t}-K_{t}
$$

and profit maximization leads to the first order condition:

$$
I_{t}=A_{h}\left(\omega Q_{t} A_{h}\right)^{\frac{\omega}{1-\omega}}
$$

The budget constraint of the household becomes

$$
C_{t}+Q_{t}\left(H_{t}-(1-\delta) H_{t-1}\right)+\frac{1+i_{t-1}}{1+\pi_{t}} B_{t-1}=W_{t} N_{t}+\Pi_{t}+T_{t}+B_{t}
$$

Market clearing in the durable asset market now requires

$$
H_{t}=(1-\delta) H_{t-1}+I_{t}
$$

The equilibrium is defined analogously to section 4. Agents do not know the market clearing condition (62), but instead hold subjective beliefs that the asset price follows equations (12)-(13). Beliefs about the hidden state $\mu_{t}$ are updated using the Kalman filter as before, and expectations about the remaining equilibrium objects satisfy conditional model consistency as defined in section 4 .

\subsection{Linearized equilibrium}

We relegate the complete description of the linearized equilibrium to the appendix. Importantly, the natural real rate of interest in the model with asset production continues to be increasing in the asset price belief $\hat{\mu}_{t}$. As before, we can write the PLM under sticky prices in deviation from the flexible price PLM:

$$
\begin{aligned}
\pi_{t} & =\beta \mathbb{E}_{t}^{\mathcal{P}} \pi_{t+1}+\kappa\left(\tilde{c}_{t}+\kappa_{1}\left(\tilde{h}_{t}-(1-\delta) \tilde{h}_{t-1}\right)\right)+\eta_{t} \\
i_{t} & =\gamma\left(\mathbb{E}_{t} \tilde{c}_{t+1}-\tilde{c}_{t}\right)+\mathbb{E}_{t} \pi_{t+1}+r_{t}^{n, P L M} \\
\theta \tilde{h}_{t} & =\gamma \tilde{c}_{t}-\beta(1-\delta) \gamma \mathbb{E}_{t} \tilde{c}_{t+1} .
\end{aligned}
$$




\subsection{Welfare functions}

We can derive a quadratic approximation of welfare to evaluate different policies. If we evaluate welfare under the actual law of motion, then welfare takes the form $-\sum_{t=0}^{\infty} \mathbb{E}_{0} \mathcal{L}_{t}$, where the period loss function is given by

$$
\begin{aligned}
\mathcal{L}_{t} & =2 \sigma \frac{\xi}{1-\xi} \frac{1}{1-\beta \xi} \pi_{t}^{2}+\left(\gamma \frac{\bar{C}}{\bar{Y}}+\frac{1-\alpha+\phi}{\alpha} \frac{\bar{C}^{2}}{\bar{Y}^{2}}\right) \hat{c}_{t}^{2}+(1-\beta(1-\delta)) \theta \frac{\bar{Q} \bar{H}}{\bar{Y}} \hat{h}_{t}^{2} \\
& +\left(\frac{1-\alpha+\phi}{\alpha} \frac{\bar{Q}^{2} \bar{H}^{2}}{\bar{Y}^{2}}+(1-\omega) \frac{\bar{Q} \bar{H}}{\bar{Y}}\right)\left(\hat{h}_{t}-(1-\delta) \hat{h}_{t-1}\right)^{2} \\
& +2 \frac{1-\alpha+\phi}{\alpha} \frac{\bar{C}}{\bar{Y}} \frac{\bar{Q} \bar{H}}{\bar{Y}}\left(c_{t}-c_{t}^{n, R E}\right)\left(\hat{h}_{t}-(1-\delta) \hat{h}_{t-1}\right) .
\end{aligned}
$$

Compared to the standard New Keynesian model, we have to take into account variation in the asset stock $h_{t}$ that the household owns, as well as variations in asset investment $\tilde{h}_{t}$. As before, the rational expectations equilibrium under flexible prices is first-best efficient, and the loss function can therefore be written in deviations from it.

By contrast, under the PLM, welfare is approximated by $-\sum_{t=0}^{\infty} \mathbb{E}_{0}^{\mathcal{P}} \mathcal{L}_{t}^{P L M}$, where the period loss function is given by

$$
\begin{aligned}
\mathcal{L}_{t}^{P L M} & =2 \sigma \frac{\xi}{1-\xi} \frac{1}{1-\beta \xi} \pi_{t}^{2}+\left(\gamma \frac{\bar{Y}}{\bar{C}}+\frac{1-\alpha+\phi}{\alpha} \frac{\bar{C}^{2}}{\bar{Y}^{2}}\right) \tilde{c}_{t}^{2}-(1-\beta(1-\delta)) \theta \frac{\bar{Q} \bar{H}}{\bar{Y}} \tilde{h}_{t}^{2} \\
& +\frac{1-\alpha+\phi}{\alpha}\left(\frac{\bar{Q} \bar{H}}{\bar{Y}}\right)^{2}\left(\tilde{h}_{t}-(1-\delta) \tilde{h}_{t-1}\right)^{2} \\
& +2\left(\gamma \frac{\bar{Y}}{\bar{C}}+\frac{1-\alpha+\phi}{\alpha}\right) \frac{\bar{C}}{\bar{Y}} \frac{\bar{Q} \bar{H}}{\bar{Y}} \tilde{c}_{t}\left(\tilde{h}_{t}-(1-\delta) \tilde{h}_{t-1}\right) .
\end{aligned}
$$

\subsection{Numerical results}

We illustrate the dynamics of the model with a simple calibration. We take the same parameters as in the baseline model, and in addition set $\omega=0.636$, corresponding to an elasticity of housing supply of 1.75 , as estimated by Saiz (2010). The rate of depreciation of the asset is set to $\delta=0.007$, corresponding to $2.8 \%$ yearly depreciation of housing (Harding et al., 2007).

Figure (6) illustrates that learning has real effects in this model with production even under flexible prices. It compares the flexible price-responses to a productivity shock under rational expectations and learning. As before, learning increases asset price volatility. But asset production now responds to asset demand, diverting resources away from consumption in an asset price boom.

As was the case with the baseline model, strict inflation targeting requires the policymaker to track 
Figure 6: Effect of learning under flexible prices, with asset production.
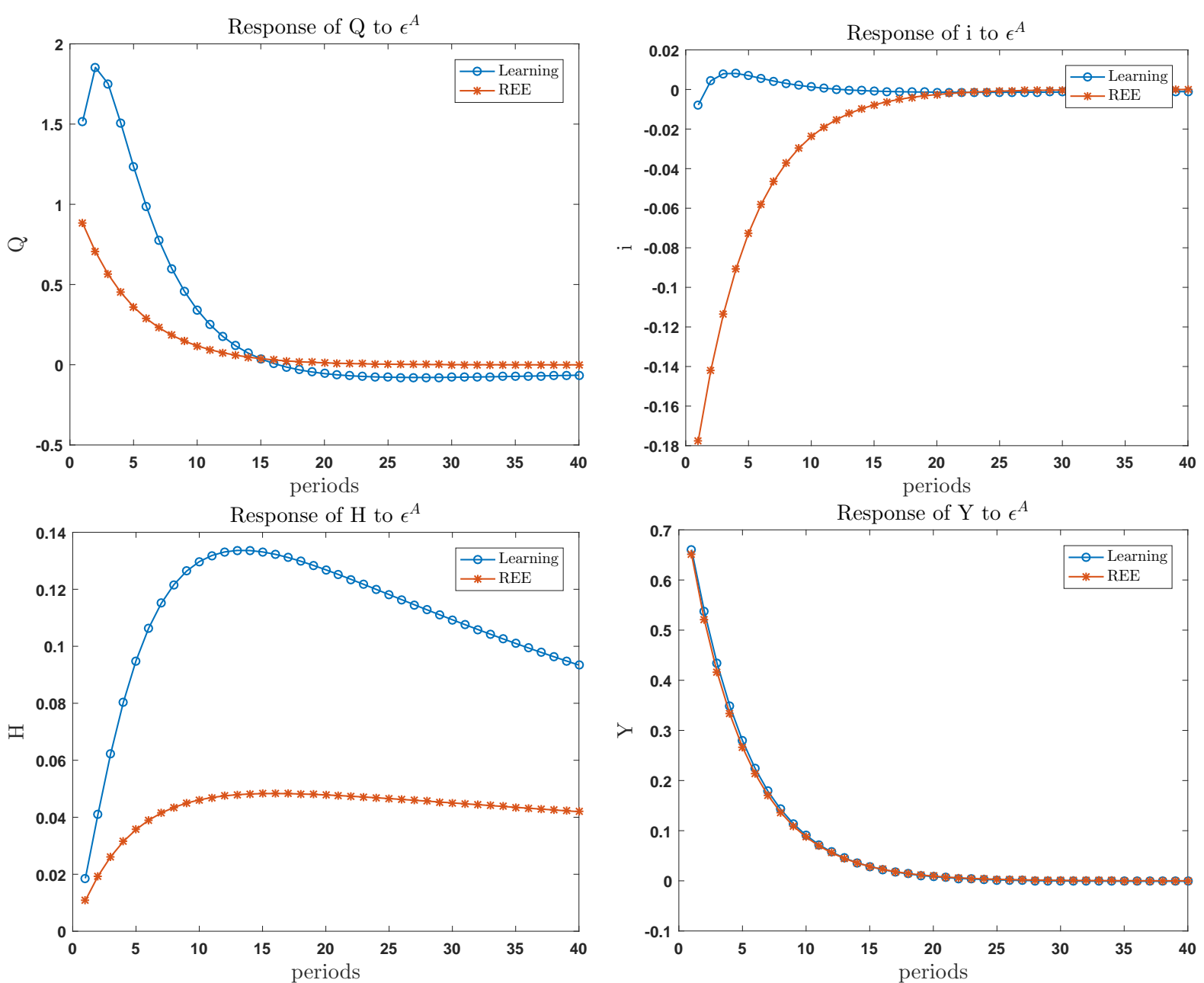

Note: Response to a one standard deviation positive technology shock $\varepsilon_{A t}$. Log percentage points. Flexible prices and zero inflation, with asset production.

movements in the natural rate of interest in the PLM; but this is no longer optimal. This is illustrated in figure 7 , which shows responses to a one standard deviation productivity shock for rules $47-49$. The figure shows that when the central bank sets interest rates according to the perceived natural rate of interest $r_{t}^{n, P L M}$, it achieves strict inflation targeting as before, and therefore implements the flexible price allocation under learning. But this allocation is inefficient because of the investment decisions taken under non-rational expectations and the housing gap $\hat{h}_{t}$ is not closed. Tracking the equilibrium (ALM) process of the natural rate delivers even worse outcomes. The standard Taylor rule, by contrast, manages to keep the housing gap relatively small following a technology shock, but does not stabilize inflation and also does not close the consumption gap $\hat{c}_{t}$ as much as rule 47 . Therefore, this extension of the model features a non-trivial policy tradeoff even without cost-push shocks.

With an investment channel present, learning does not only change how monetary poloicy has to be implemented, but also the optimal target criterion. In Table 2, we compare strict inflation targeting in 
Figure 7: Inflation targeting vs Taylor rule, with asset production.
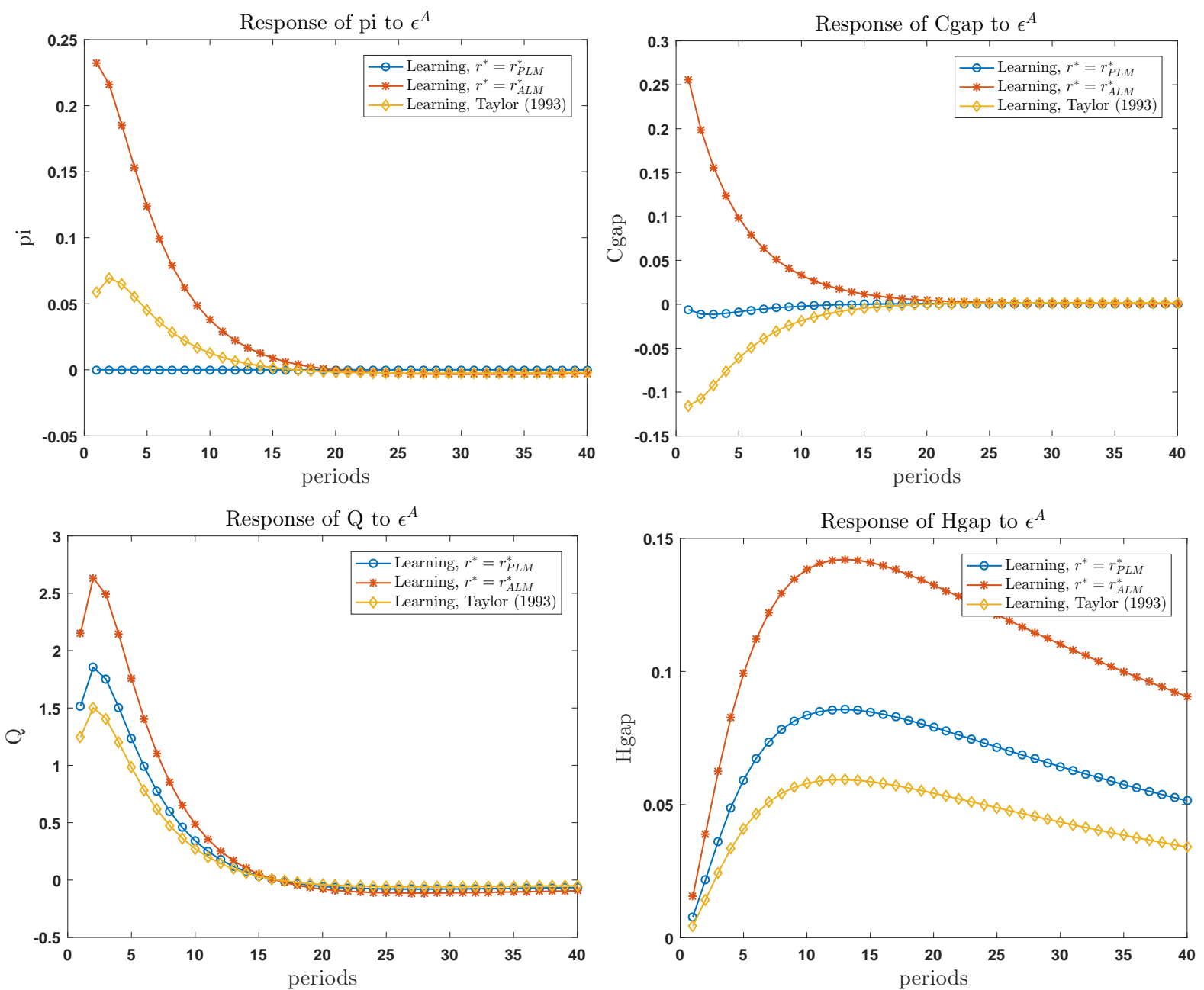

Note: Response to a unit standard deviation positive technology shock $\varepsilon_{A t}$ under sticky prices and with asset production. Log percentage points. The interest rate rules used are given in Equations (47) (using the PLM natural rate with asset production) and (49).

the absence of cost-push shocks with a targeting rule that explicitly "leans against the wind", in that it tolerates inflation below target at times when asset prices are high. This targeting rule would be suboptimal under rational expectations, but turns out to be welfare-increasing under learning.

We also compute optimal simple rules of the form (53) for our calibration of the model with costpush shocks, as in section 7. The results are tabulated in Table 3. As can be seen in rows (7)-(9), in the absence of an outgap gap response the optimal rule has a negative coefficient on the asset price term. This a result of the allocative inefficiency that learning introduces under asset production. The optimal choice of $\phi_{q}$ in this case is driven by the need to control of inefficient under/over investment under learning. As was the case with fixed asset supply, however, the optimal simple rule exibits a positive response to both asset prices and the output gap, with optimal rule coefficients prescribing a more aggressive reaction to both the otput gap and asset prices under learning than in the case with fixed asset supply. 
Table 2: "Leaning against the wind" with asset production.

\begin{tabular}{l|ccccc} 
Rational Expectations & $\sigma\left(\pi_{t}\right)$ & $\sigma\left(\hat{y}_{t}\right)$ & $\sigma\left(\Delta \hat{h}_{t}\right)$ & $\sigma\left(\Delta q_{t}\right)$ & $\mathcal{L}$ \\
\hline$\pi_{t}=0$ & 0.000 & 0.000 & 0.000 & 0.930 & 0 \\
\hline Learning & $\sigma\left(\pi_{t}\right)$ & $\sigma\left(\hat{y}_{t}\right)$ & $\sigma\left(\Delta \hat{h}_{t}\right)$ & $\sigma\left(\Delta q_{t}\right)$ & $\mathcal{L}$ \\
\hline$\pi_{t}=0$ & 0.000 & 0.037 & 4.413 & 1.661 & 31.67 \\
$\pi_{t}=-.311 \hat{\mu}_{t-1}$ & 0.389 & 0.026 & 4.369 & 1.659 & 31.31 \\
\hline
\end{tabular}

Table 3: Performance of optimized simple rules, with asset production.

\begin{tabular}{|c|c|c|c|c|c|c|}
\hline & Rational Expectations & $\sigma\left(\pi_{t}\right)$ & $\sigma\left(\hat{c}_{t}\right)$ & $\sigma\left(\hat{h}_{t}\right)$ & $\sigma\left(\Delta q_{t}\right)$ & $\mathcal{L}$ \\
\hline (1) & $i_{t}=r_{s s}+1.5 \pi_{t}+0.125 \cdot \hat{y}_{t}$ & 0.342 & 0.470 & 0.000 & 0.759 & 0.779 \\
\hline (2) & $\begin{array}{l}i_{t}=\rho_{i}^{*} i_{t-1}+\left(1-\rho_{i}^{*}\right) \cdot\left(r_{s s}+1.5 \pi_{t}+\phi_{y}^{*} \cdot \hat{y}_{t}\right) \\
\quad\left\{\rho_{i}^{*}, \phi_{y}^{*}\right\}=\{0.723,1.207\}\end{array}$ & 0.365 & 0.271 & 0.000 & 0.675 & 0.475 \\
\hline \multirow[t]{2}{*}{ (3) } & $\begin{array}{l}\pi_{t}=\zeta^{*} \eta_{t} \\
\zeta^{*}=0.214\end{array}$ & 0.299 & 0.296 & 0.000 & 0.968 & 0.401 \\
\hline & Learning & $\sigma\left(\pi_{t}\right)$ & $\sigma\left(\hat{c}_{t}\right)$ & $\sigma\left(\hat{h}_{t}\right)$ & $\sigma\left(\Delta q_{t}\right)$ & $\mathcal{L}$ \\
\hline (4) & $\begin{array}{l}i_{t}=\rho_{i}^{*} i_{t-1}+\left(1-\rho_{i}^{*}\right) \cdot\left(r_{s s}+1.5 \pi_{t}+\phi_{y}^{*} \cdot \hat{y}_{t}\right) \\
\quad\left\{\rho_{i}^{*}, \phi_{y}^{*}\right\}=\{0.098,0.819\}\end{array}$ & 1.024 & 0.512 & 0.193 & 1.078 & 6.207 \\
\hline (5) & $\begin{array}{c}\pi_{t}=\zeta^{*} \eta_{t} \\
\zeta^{*}=0.399\end{array}$ & 0.566 & 0.034 & 0.494 & 1.662 & 32.413 \\
\hline (6) & $\begin{array}{l}i_{t}=\rho_{i}^{*} i_{t-1}+\left(1-\rho_{i}^{*}\right) \cdot\left(r_{s s}+1.5 \pi_{t}\right) \\
\quad \rho_{i}^{*}=0\end{array}$ & 0.045 & 0.602 & 0.747 & 1.923 & 60.771 \\
\hline (7) & $\begin{array}{l}\text { BG }(1999) \mathrm{w} / \text { asset price } \\
\quad i_{t}=\rho_{i}^{*} i_{t-1}+\left(1-\rho_{i}^{*}\right) \cdot\left(r_{s s}+1.5 \pi_{t}+\phi_{q}^{*} \cdot \log q_{t-1}\right) \\
\quad\left\{\rho_{i}^{*}, \phi_{q}^{*}\right\}=\{0,-0.241\}\end{array}$ & 1.735 & 0.693 & 0.744 & 0.778 & 46.412 \\
\hline (8) & $\begin{array}{l}\text { BG }(2001) \mathrm{w} / \text { asset price } \\
\quad i_{t}=\rho_{i}^{*} i_{t-1}+\left(1-\rho_{i}^{*}\right) \cdot\left(r_{s s}+1.5 \pi_{t}+\phi_{q}^{*} \cdot \log q_{t}\right) \\
\quad\left\{\rho_{i}^{*}, \phi_{q}^{*}\right\}=\{0,-0.072\}\end{array}$ & 0.697 & 0.596 & 0.742 & 1.925 & 59.715 \\
\hline (9) & $\begin{array}{l}i_{t}=\rho_{i}^{*} i_{t-1}+\left(1-\rho_{i}^{*}\right) \cdot\left(r_{s s}+1.5 \pi_{t}+\phi_{q}^{*} \cdot \sum_{s=0}^{\infty} \omega^{* s} \Delta \log Q_{t-s}\right) \\
\quad\left\{\rho_{i}^{*}, \phi_{q}^{*}, \omega^{*}\right\}=\{0,-0.064,0.999\}\end{array}$ & 0.618 & 0.598 & 0.744 & 1.927 & 59.956 \\
\hline (10) & $\begin{array}{l}\text { FM }(2007) \mathrm{w} / \text { asset price } \\
\qquad i_{t}=\rho_{i}^{*} i_{t-1}+\left(1-\rho_{i}^{*}\right) \cdot\left(r_{s s}+1.5 \pi_{t}+\phi_{y}^{*} \cdot \hat{y}_{t}+\phi_{q}^{*} \cdot \log q_{t}\right) \\
\quad\left\{\rho_{i}^{*}, \phi_{y}^{*}, \phi_{q}^{*}\right\}=\{0.330,3.548,1.077\}\end{array}$ & 0.638 & 0.559 & 0.096 & 0.927 & 2.131 \\
\hline$(11)^{*}$ & $\begin{array}{l}i_{t}=\rho_{i}^{*} i_{t-1}+\left(1-\rho_{i}^{*}\right) \cdot\left(r_{s s}+1.5 \pi_{t}+\phi_{y}^{*} \cdot \hat{y}_{t}+\phi_{q}^{*} \cdot \sum_{s=0}^{\infty} \omega^{* s} \Delta \log Q_{t-s}\right) \\
\quad\left\{\rho_{i}^{*}, \phi_{y}^{*}, \phi_{q}^{*}, \omega^{*}\right\}=\{0.329,3.106,0.974,0.999\}\end{array}$ & 0.646 & 0.570 & 0.095 & 0.923 & 2.155 \\
\hline
\end{tabular}




\section{Conclusion}

In this paper, we have characterized optimal monetary policy in a model in which agents are learning about asset prices. Our model is the standard New-Keynesian model with a durable asset in fixed supply. Agents form expectations about asset price in an extrapolative fashion. However, their expectations remain model-consistent conditional on their beliefs about house prices, which allows us to isolate the effects of learning about asset prices from the many other ways in which distorted beliefs can affect the economy. Learning amplifies asset price fluctuations in the model, and leads to perceived wealth effects that create inefficient fluctuations in aggregate demand.

We gave an analytical solution to the optimal policy in the linearized model with learning, and have showed that inflation targeting remains optimal. However, inflation targeting requires a very different prescription for the nominal interest rate under learning. The interest rate has to increase with asset prices and subjective expectations of future asset price growth. We then showed using numerical simulations that the optimal policy can be reasonably well approximated by simple rules that responds to inflation and a moving average of asset price growth. A reaction to asset prices always reduces asset price volatility, but too much of a reaction can increase inflation volatility. Nonetheless, the optimal weight on asset prices is strictly positive for the rules we considered.

We have also shown that our theoretical results are robust to the specification of subjective beliefs, encompassing a wide range of belief specifications. Another extension of our model showed that the case for reacting to asset prices is strengthened further when investment decisions are affected by asset prices. With an investment channel, it becomes beneficial to include a reaction to asset prices in the targeting rule of monetary policy. This "leaning against the wind" policy effectively curbs inefficient investment fluctuations. 


\section{References}

Adam, K., Kuang, P. and Marcet, A. (2012). House price booms and the current account. NBER Macroeconomics Annual, 26 (1), 77-122.

-, Marcet, A. and Beutel, J. (2017). Stock price booms and expected capital gains. American Economic Review, 107 (8), 2352-2408.

—, — and Nicolini, J. P. (2015). Stock market volatility and learning. Journal of Finance.

- and Woodford, M. (2018). Leaning Against Housing Prices as Robustly Optimal Monetary Policy. Working Paper 24629, NBER.

Airaudo, M. (2016). Monetary Policy and Asset Prices with Infinite-Horizon Learning. Tech. rep.

Barberis, N., Greenwood, R., Jin, L. and Shleifer, A. (2015). X-CAPM: An extrapolative capital asset pricing model. Journal of Financial Economics, 115 (1), 1-24.

Bean, C. R. (2004). Asset prices, financial instability, and monetary policy. The American Economic Review, 94 (2), 14-18.

Bernanke, B. S. and Gertler, M. (1999). Monetary policy and asset price volatility. Economic Review - Federal Reserve Bank of Kansas City, Q IV, 17-62.

- and - (2001). Should central banks respond to movements in asset prices? American Economic Review, 91 (2), 253-257.

Billi, R. M. (2017). Price Level Targeting and Risk Management. Working Paper Series 302, Sveriges Riksbank.

Boenm, C. E. and House, C. L. (2014). Optimal Taylor Rules in New Keynesian Models. Working Paper 20237, NBER.

Bordalo, P., Gennaiola, N. and Shleifer, A. (2018). Diagnostic expectations and credit cycles. Journal of Finance, 73 (1), 199-227.

Caines, C. (2016). Can Learning Explain Boom-Bust Cycles In Asset Prices? An Application to the US Housing Boom. International Finance Discussion Papers 1181, Board of Governors of the Federal Reserve System (U.S.).

Christiano, L., Ilut, C., Motto, R. and Rostagno, M. (2010). Monetary policy and stock market booms. Proceedings, Jackson Hole Economic Policy Symposium, pp. 85-145.

Collin-Dufresne, P., Johannes, M. and Lochstoer, L. A. (2013). Parameter Learning in General Equilibrium: The Asset Pricing Implications. NBER Working Papers 19705, National Bureau of Economic Research, Inc.

Dong, F., MiaO, J. and Wang, P. (2017). Asset Bubbles and Monetary Policy. Working paper.

Dupor, B. (2005). Stabilizing non-fundamental asset price movements under discretion and limited information. Journal of Monetary Economics, 52 (4), 727 - 747.

Eusepi, S., Giannoni, M. and Preston, B. (2015). The Limits of Monetary Policy with Long-term Drift in Expectations. Working paper.

— and Preston, B. (2016). The science of monetary policy: an imperfect knowledge perspective. Staff Reports 782, Federal Reserve Bank of New York. 
Faia, E. and Monacelli, T. (2007). Optimal interest rate rules, asset prices, and credit frictions. Journal of Economic Dynamics and Control, 31 (10), 3228-3254.

Fuster, A., Hebert, B. and Laibson, D. (2012). Natural expectations, macroeconomic dynamics, and asset pricing. In D. Acemoglu and M. Woodford (eds.), NBER Macroeconomics Annual 2011, NBER Chapters, vol. 26, National Bureau of Economic Research, pp. 1-48.

Gabaix, X. (2016). A Behavioral New Keynesian Model. NBER Working Papers 22954, National Bureau of Economic Research, Inc.

GaLI, J. (2014). Monetary policy and rational asset price bubbles. American Economic Review, 104 (3), $721-752$.

- (2017). Monetary Policy and Bubbles in a New Keynesian Model with Overlapping Generations. Working Paper 959, Barcelona GSE.

Gandelman, N. and Hernández-Murillo, R. (2014). Risk Aversion at the Country Level. Working paper series, Federal Reserve Bank of St. Louis.

GANDRÉ, P. (2017). Learning, house prices and macro-financial linkages. Working paper.

Glaeser, E. L. and Nathanson, C. G. (2017). An extrapolative model of house price dynamics. Journal of Financial Economics.

Greenwood, R. and Shleifer, A. (2014). Expectations of returns and expected returns. Review of Financial Studies, 27 (3), 714-746.

Harding, J. P., Rosenthal, S. S. and Sirmans, C. (2007). Depreciation of housing capital, maintenance, and house price inflation: Estimates from a repeat sales model. Journal of Urban Economics, $61(2), 193-217$.

Laubach, T. and Williams, J. C. (2016). Measuring the natural rate of interest redux. Business Economics, 51, 257-267.

Mertens, T. M. (2011). Volatile Stock Markets: Equilibrium Computation and Policy Analysis. Working paper, Federal Reserve Bank of San Francisco.

Molnar, K. and SAntoro, S. (2014). Optimal monetary policy when agents are learning. European Economic Review, 66, 39 - 62.

Neiss, K. S. and NeLson, E. (2003). The real-interest-rate gap as an inflation indicator. Macroeconomic Dynamics, 7 (2), 239-262.

Preston, B. (2006). Adaptive learning, forecast-based instrument rules and monetary policy. Journal of Monetary Economics, 53 (3), 507 - 535.

SAIz, A. (2010). The geographic determinants of housing supply. Quarterly Journal of Economics, $125(3), 1253-1296$.

Winkler, F. (2016). The Role of Learning for Asset Prices, Business Cycles, and Monetary Policy. Finance and Economics Discussion Series 2016-019, Federal Reserve Board of Governors.

Woodford, M. (2003). Interest and prices: Foundations of a theory of monetary policy. Princeton University Press.

- (2010). Robustly optimal monetary policy with near-rational expectations. American Economic Review, 100 (1), 274-303. 


\section{A Appendix: Details on the derivations}

\section{A.1 Asset demand in the model with fixed asset supply}

The coefficients in the asset demand function (32) are:

$$
\begin{aligned}
k_{h} & =\frac{1}{2 \beta}\left(1+\beta+\frac{\theta}{\gamma \kappa_{1}}(1-\beta)-\sqrt{\left(1+\beta+\frac{\theta}{\gamma \kappa_{1}}(1-\beta)\right)^{2}-4 \beta}\right) \in(0,1) \\
k_{a} & =\frac{1+\phi}{1+\phi-\alpha(1-\gamma)} \frac{1-\beta \rho_{a}}{\kappa_{1}+(1-\beta) \frac{\theta}{\gamma}+\beta \kappa_{1}\left(1-k_{h}-\rho_{a}\right)}>0 \\
k_{q} & =\frac{1}{\gamma} \frac{1-\beta}{(1-\beta) \frac{\theta}{\gamma}+\kappa_{1}\left(1-\beta k_{h}\right)}>0 \\
k_{\mu} & =\frac{\beta / \gamma}{(1-\beta) \frac{\theta}{\gamma}+\kappa_{1}\left(1-\beta \rho_{\mu}+\beta\left(1-k_{h}\right)\right)} \frac{(1+\beta) \frac{\theta}{\gamma}+\kappa_{1} \beta\left(1-k_{h}\right)}{(1+\beta) \frac{\theta}{\gamma}+\kappa_{1}\left(1-\beta k_{h}\right)}>0
\end{aligned}
$$

\section{A.2 Asset demand with extended beliefs}

The coefficients $\tilde{k}_{\mu}$ and $\tilde{\rho}$ read as follows:

$$
\begin{aligned}
\tilde{k}_{\mu} & =\frac{1}{\gamma} \frac{\beta}{(1-\beta) \frac{\theta}{\gamma}+\kappa_{1}\left(1+\beta-\beta k_{h}\right)} \frac{(1+\beta) \frac{\theta}{\gamma}+\kappa_{1} \beta\left(1-k_{h}\right)}{(1+\beta) \frac{\theta}{\gamma}+\kappa_{1}\left(1-\beta k_{h}\right)}>0 \\
\tilde{\rho} & =\frac{\beta}{\beta+(1-\beta) \frac{\theta}{\gamma \kappa_{1}}+\left(1-\beta k_{h}\right)} \in(0,1) .
\end{aligned}
$$

\section{A.3 Attaining the first-best allocation with cost push shocks under learning}

Substituting the policy $\pi_{t}=-\left(\beta \rho_{\eta}\right)^{-1} \eta_{t}+b_{t} z_{t}$ into the Phillips curve (38), we obtain:

$$
\pi_{t}=-\left(\beta \rho_{\eta}\right)^{-1} \eta_{t}+b_{t} z_{t}=\kappa\left(\tilde{c}_{t}+\kappa_{1} \Delta \tilde{h}_{t}\right)
$$

We will find $b_{t}$ such that $\pi_{t}=0$ a.s. under the ALM. In this case, $\kappa\left(\tilde{c}_{t}+\kappa_{1} \Delta \tilde{h}_{t}\right)=y_{t}-y_{t}^{R E}=0$ under the ALM as well, and the first-best allocation is attained.

In order to solve for $b_{t}$, then, we need to compute the equilibrium value of $z_{t}$, which amounts to solving for the equilibrium price $q_{t}$. To do this, we first need to derive the demand function for the asset under the PLM. Let $x_{t}=\tilde{c}_{t}+\kappa_{1} \Delta \tilde{h}_{t}$. In analogy to the computations of the flexible-price equilibrium, 
we can compute the asset demand function as the solution to the following system of equations:

$$
\begin{aligned}
(1-\beta) \theta h_{t} & =\gamma c_{t}-q_{t}-\beta \mathbb{E}_{t}^{\mathcal{P}}\left[\gamma c_{t+1}-q_{t+1}\right] \\
(1+\phi-\alpha+\alpha \gamma) c_{t} & =\alpha x_{t}+(1-\alpha) a_{t}-(1+\phi-\alpha) \frac{\bar{Q} \bar{H}}{\bar{Y}} \Delta h_{t} .
\end{aligned}
$$

With $x_{t}=\left(b_{t} z_{t}-\left(\beta \rho_{\eta}\right)^{-1} \eta_{t}\right) / \kappa$, we can solve:

$$
h_{t}=k_{h} h_{t-1}+k_{a} a_{t}-k_{q} q_{t}+k_{\mu} \hat{\mu}_{t-1}+k_{b z} b_{t} z_{t}+k_{\eta} \eta_{t} .
$$

Here, the coefficients $k_{h}, k_{a}, k_{q}$ and $k_{\mu}$ are the same as in the flexible-price demand function (32). The coefficients $k_{\eta}$ and $k_{b z}$ are given by:

$$
\begin{aligned}
k_{\eta} & =-\frac{k_{h}}{\beta \rho_{\eta} \kappa} \frac{1-\beta \rho_{\eta}}{1-k_{h} \beta \rho_{\eta}} \frac{\bar{Y}}{\bar{Q} \bar{H}} \frac{\alpha}{1+\phi-\alpha} \\
k_{z, t} & =-\frac{k_{h}}{\kappa} \frac{\bar{Y}}{\bar{Q} \bar{H}} \frac{\alpha}{1+\phi-\alpha}
\end{aligned}
$$

Now the ALM is found by imposing $h_{t}=0$, and this condition leads to the ALM expression for $z_{t}$ :

$$
z_{t}=\frac{k_{q}}{k_{q}-k_{b z} b_{t}}\left(\frac{1}{k_{q}}\left(k_{a} a_{t}+k_{\mu} \hat{\mu}_{t-1}+k_{\eta} \eta_{t}\right)-q_{t-1}-\hat{\mu}_{t-1}\right)
$$

Imposing $\beta \rho_{\eta} b_{t} z_{t}=\eta_{t}$ then leads to:

$$
b_{t}=\left(\frac{k_{b z}}{k_{q}}+\frac{\beta \rho_{\eta}}{k_{q}}\left(k_{a} a_{t}+k_{\mu} \hat{\mu}_{t-1}+k_{\eta} \eta_{t}\right)-\beta \rho_{\eta}\left(q_{t-1}+\hat{\mu}\right)\right)^{-1} \eta_{t} .
$$

\section{A.4 Replication of RE-optimal policy with cost push shocks under learning}

The solution undear learning must be obtained again by first solving the PLM and then imposing equilibrium. We start by imposing (50) as a targeting rule in the PLM. We can make use of the fact that we can represent the equilibrium conditions of the PLM by the three equation (38)-(40). Substituting the targeting rule yields:

$$
\begin{aligned}
& \tilde{c}_{t}=-\frac{1-\zeta(1-\beta \rho)}{\kappa} \eta_{t}-\kappa_{1} \Delta \tilde{h}_{t} \\
& \tilde{h}_{t}=-\frac{\gamma}{\theta(1-\beta)} \beta \mathbb{E}_{t}^{\mathcal{P}} \Delta \tilde{c}_{t+1} .
\end{aligned}
$$


This system has one state variable, the asset holding gap $\tilde{h}_{t-1}$, and one shock, the cost-push shock $\eta_{t}$. Using the method of undetermined coefficients leads to the following solution:

$$
\begin{aligned}
\tilde{c}_{t} & =a \tilde{h}_{t-1}+b \eta_{t} \\
\tilde{h}_{t} & =\gamma \frac{a \tilde{h}_{t-1}+b(1-\beta \rho) \eta_{t}}{\theta(1-\beta)+\gamma \beta a}
\end{aligned}
$$

where

$$
\begin{aligned}
& a=\frac{1-\beta}{\beta} \frac{\sqrt{\left(\theta+\gamma \kappa_{1}\right)^{2}+4 \frac{\beta}{1-\beta} \gamma \kappa_{1} \theta}-\left(\theta+\gamma \kappa_{1}\right)}{2 \gamma} \\
& b=-\frac{1-\zeta(1-\beta \rho)}{\kappa}\left(1+\frac{\kappa_{1} \gamma(1-\beta \rho)}{\theta(1-\beta)+\gamma \beta a}\right)^{-1} .
\end{aligned}
$$

We can substitute this solution into the IS equation (39) to solve for the implied nominal interest rate path to obtain:

$$
i_{t}=r_{t}^{n, P L M}+\rho \eta_{t}-\gamma\left(a \Delta \tilde{h}_{t}+b(1-\rho) \eta_{t}\right)
$$

We can equivalently rewrite the purchases of assets in terms of the perceived output gap and inflation by observing that $\eta_{t}=\pi_{t} / \zeta$ and

$$
\begin{aligned}
\kappa_{1} \Delta \tilde{h}_{t} & =-\frac{1-\zeta(1-\beta \rho)}{\kappa} \eta_{t}-\tilde{c}_{t} \\
& =-\frac{1-\zeta(1-\beta \rho)}{\kappa} \eta_{t}-\tilde{y}_{t}+\frac{\bar{Q} \bar{H}}{\bar{Y}} \Delta \tilde{h}_{t} \\
& =\frac{1+\phi-\alpha}{\kappa_{1} \alpha \gamma}\left(\frac{1-\zeta(1-\beta \rho)}{\kappa} \eta_{t}+\tilde{y}_{t}\right) .
\end{aligned}
$$

We can then express the interest rate as a function of the perceived natural rate, inflation and the perceived output gap:

$$
i_{t}=r_{t}^{n, P L M}+a \frac{1+\phi-\alpha}{\kappa_{1} \alpha} \tilde{y}_{t}+\left(\rho-\gamma(1-\rho) b+a \frac{1+\phi-\alpha}{\kappa_{1} \alpha} \frac{1-\zeta(1-\beta \rho)}{\kappa}\right) \frac{1}{\zeta} \pi_{t} .
$$

This expression shows that the equilibrium interest rate path depends on inflation and the perceived output gap as well as the natural rate. The natural rate is increasing in the level of asset prices as well as the subjective expectation of future asset price growth. Therefore, the nominal interest rate in (88) is effectively leaning against the wind.

In the second step, we solve for the equilibrium (ALM) allocation and prices. Imposing asset market 
clearing requires $h_{t}=0$, which can be rewritten as

$$
h_{t}^{n, P L M}=-\tilde{h}_{t} .
$$

Substituting this into the expression for asset demand (32), we can solve for the equilibrium price:

$$
\begin{aligned}
-\tilde{h}_{t} & =k_{a} a_{t}-k_{h} \tilde{h}_{t-1}+k_{q} q_{t}+k_{\mu} \hat{\mu}_{t-1} \\
\Rightarrow q_{t} & =-\frac{1}{k_{q}}\left(k_{a} a_{t}+k_{\mu} \hat{\mu}_{t-1}+\tilde{h}_{t}-k_{h} \tilde{h}_{t-1}\right) .
\end{aligned}
$$

Finally, we solve for the equilibrium output gap. We first rewrite Equation (33) in terms of housing purchases under flexible prices:

$$
y_{t}^{n, P L M}=y_{t}^{n, R E}+\frac{\alpha \gamma \kappa_{1}}{1+\phi-\alpha}\left(h_{t}^{n, P L M}-h_{t-1}^{n, P L M}\right)
$$

and use this relationship to arrive at the main result in this section:

$$
\begin{aligned}
\hat{y}_{t} & =\tilde{h}_{t}+y_{t}^{n, P L M}-y_{t}^{n, R E} \\
& =\tilde{c}_{t}+\frac{\bar{Q} \bar{H}}{\bar{Y}} \Delta \tilde{h}_{t}+y_{t}^{n, P L M}-y_{t}^{n, R E} \\
& =\tilde{c}_{t}+\left(\frac{\bar{Q} \bar{H}}{\bar{Y}}-\frac{\alpha \gamma \kappa_{1}}{1+\phi-\alpha}\right) \Delta \tilde{h}_{t} \\
& =\tilde{c}_{t}+\kappa_{1} \Delta \tilde{h}_{t} \\
& =-\frac{1-\zeta(1-\beta \rho)}{\kappa} \eta_{t} .
\end{aligned}
$$

That is, the equilibrium path of the output gap is identical to that under rational expectations.

\section{A.5 Linearized equilibrium conditions and natural rate in the model with asset production}

Under rational expectations, the following set of equations describe the linearized equilibrium (up to a monetary policy rule): 


$$
\begin{aligned}
y_{t} & =a_{t}+\alpha n_{t} \\
\pi_{t} & =\beta \pi_{t+1}+\frac{(1-\xi)(1-\beta \xi)}{\xi}\left(w_{t}-a_{t}+(1-\alpha) n_{t}\right)+\eta_{t} \\
w_{t} & =\gamma c_{t}+\phi n_{t} \\
\bar{Y} y_{t} & =\bar{C} c_{t}+\bar{Q} \bar{H}\left(h_{t}-(1-\delta) h_{t-1}\right) \\
h_{t} & =(1-\delta) h_{t-1}+\frac{\omega \delta}{1-\omega} q_{t} \\
i_{t} & =\gamma\left(\mathbb{E}_{t} c_{t+1}-c_{t}\right)+\mathbb{E}_{t} \pi_{t+1} \\
q_{t} & =\gamma c_{t}-(1-\beta(1-\delta)) \theta h_{t}-\beta(1-\delta) \gamma \mathbb{E}_{t} c_{t+1}+\beta \delta \mathbb{E}_{t} q_{t+1} .
\end{aligned}
$$

We can eliminate the asset price, wages, labor and output from this to get a three-equation system:

$$
\begin{gathered}
\pi_{t}=\beta \mathbb{E}_{t} \pi_{t+1}+\frac{(1-\xi)(1-\beta \xi)}{\xi} . \\
\left(\gamma c_{t}+\left(\frac{1+\phi-\alpha}{\alpha}\right)\left(\frac{\bar{C}}{\bar{Y}} c_{t}+\frac{\bar{Q} \bar{H}}{\bar{Y}}\left(h_{t}-(1-\delta) h_{t-1}\right)\right)-\frac{1+\phi}{\alpha} a_{t}\right)+\eta_{t} \\
i_{t}=\gamma\left(\mathbb{E}_{t} c_{t+1}-c_{t}\right)+\mathbb{E}_{t} \pi_{t+1} \\
(1-\tilde{\beta}) \theta h_{t}=\gamma c_{t}-\frac{1-\omega}{\omega \delta}\left(h_{t}-(1-\delta) h_{t-1}\right)-\tilde{\beta} \gamma \mathbb{E}_{t} c_{t+1}+\tilde{\beta} \frac{1-\omega}{\omega \delta} \mathbb{E}_{t}\left(h_{t+1}-(1-\delta) h_{t}\right)
\end{gathered}
$$

where we introduced $\tilde{\beta}=\beta(1-\delta)$ to ease notation.

Under learning, we can do a similar exercise. We first tackle the PLM. All we do is to replace the market clearing condition with the subjective law of motion for asset prices:

$$
\begin{aligned}
y_{t} & =a_{t}+\alpha n_{t} \\
\pi_{t} & =\beta \mathbb{E}_{t}^{\mathcal{P}} \pi_{t+1}+\frac{(1-\xi)(1-\beta \xi)}{\xi}\left(w_{t}-a_{t}+(1-\alpha) n_{t}\right)+\eta_{t} \\
w_{t} & =\gamma c_{t}+\phi n_{t} \\
\bar{Y} y_{t} & =\bar{C} c_{t}+\bar{Q} \bar{H}\left(h_{t}-(1-\delta) h_{t-1}\right) \\
i_{t} & =\gamma\left(\mathbb{E}_{t}^{\mathcal{P}} c_{t+1}-c_{t}\right)+\mathbb{E}_{t}^{\mathcal{P}} \pi_{t+1} \\
q_{t} & =\gamma c_{t}-(1-\beta(1-\delta)) \theta h_{t}-\beta(1-\delta) \gamma \mathbb{E}_{t}^{\mathcal{P}} c_{t+1}+\beta \delta \mathbb{E}_{t}^{\mathcal{P}} q_{t+1} \\
q_{t} & =q_{t-1}+\hat{\mu}_{t-1}+z_{t} \\
\hat{\mu}_{t} & =\rho_{\mu} \hat{\mu}_{t-1}+g z_{t} .
\end{aligned}
$$


The three-equation system describing the equilibrium boils down to:

$$
\begin{aligned}
\pi_{t} & =\beta \mathbb{E}_{t}^{\mathcal{P}} \pi_{t+1}+\frac{(1-\xi)(1-\beta \xi)}{\xi} . \\
& \left(\gamma c_{t}+\left(\frac{1+\phi-\alpha}{\alpha}\right)\left(\frac{\bar{C}}{\bar{Y}} c_{t}+\frac{\bar{Q} \bar{H}}{\bar{Y}}\left(h_{t}-(1-\delta) h_{t-1}\right)\right)-\frac{1+\phi}{\alpha} a_{t}\right)+\eta_{t} \\
i_{t} & =\gamma\left(\mathbb{E}_{t}^{\mathcal{P}} c_{t+1}-c_{t}\right)+\mathbb{E}_{t}^{\mathcal{P}} \pi_{t+1} \\
q_{t} & =\gamma c_{t}-(1-\tilde{\beta}) \theta h_{t}-\tilde{\beta} \gamma \mathbb{E}_{t}^{\mathcal{P}} c_{t+1}+\tilde{\beta} \mathbb{E}_{t}^{\mathcal{P}} q_{t+1} .
\end{aligned}
$$

The flexible price equilibrium under rational expectations is characterized as:

$$
\begin{aligned}
h_{t}^{n, R E}= & k_{a}^{R E} a_{t}+k_{h}^{R E} h_{t-1}^{R E}, k_{a}^{R E}>0, k_{h}^{R E} \in(0,1-\delta) \\
y_{t}^{n, R E}= & \left(\frac{\bar{C}}{\bar{Y}} \frac{\phi+1}{\overline{\bar{Y}}(1+\phi-\alpha)+\alpha \gamma}+\left(\frac{\bar{Q} \bar{H}}{\bar{Y}}-\frac{\bar{C}}{\bar{Y}} \kappa_{1}\right) k_{a}^{R E}\right) a_{t}- \\
& \left(\frac{\bar{Q} \bar{H}}{\bar{Y}}-\frac{\bar{C}}{\bar{Y}} \kappa_{1}\right)\left(1-\delta-k_{h}^{R E}\right) h_{t-1}^{R E} \\
c_{t}^{n, R E}= & \left(\frac{\phi+1}{\overline{\bar{C}}(1+\phi-\alpha)+\alpha \gamma}-\kappa_{1} k_{a}^{R E}\right) a_{t}+\kappa_{1}\left(1-\delta-k_{h}^{R E}\right) h_{t-1}^{R E} \\
r_{t}^{n, R E}= & -\gamma\left(\frac{\phi+1}{\overline{\bar{C}}(1+\phi-\alpha)+\alpha \gamma}-\kappa_{1} k_{a}^{R E}+\kappa_{1}\left(1-\delta-k_{h}^{R E}\right) k_{a}^{R E}\right)\left(1-\rho_{a}\right) a_{t} \\
& -\gamma \kappa_{1}\left(1-\delta-k_{h}^{R E}\right)\left(1-k_{h}^{R E}\right) h_{t-1}^{R E}
\end{aligned}
$$

where the constants $\kappa$ and $\kappa_{1}$ are now redefined as:

$$
\begin{aligned}
\kappa & =\frac{1-\xi}{\xi} \frac{1-\beta \xi}{\alpha}\left(\frac{\bar{C}}{\bar{Y}}(1+\phi-\alpha)+\alpha \gamma\right) \\
\kappa_{1} & =\frac{1+\phi-\alpha}{\overline{\bar{C}}(1+\phi-\alpha)+\alpha \gamma} \frac{\bar{Q} \bar{H}}{\bar{Y}} .
\end{aligned}
$$

Under learning and flexible prices, we can boil things down to these two equations to solve for the PLM:

$$
\begin{aligned}
0 & =\gamma c_{t}+\left(\frac{1+\phi-\alpha}{\alpha}\right)\left(\frac{\bar{C}}{\bar{Y}} c_{t}+\frac{\bar{Q} \bar{H}}{\bar{Y}} \tilde{h}_{t}\right)-(1+\phi) a_{t} \\
q_{t} & =\gamma c_{t}-(1-\tilde{\beta}) \theta h_{t}-\tilde{\beta} \gamma \mathbb{E}_{t} c_{t+1}+\beta \delta \mathbb{E}_{t}^{\mathcal{P}} q_{t+1} .
\end{aligned}
$$

Guess and verify

$$
h_{t}^{n, P L M}=k_{a} a_{t}+k_{h} h_{t-1}^{n, P L M}+k_{q} q_{t}+k_{\mu} \hat{\mu}_{t-1}
$$


where the coefficients are given by:

$$
\begin{aligned}
k_{h} & =\frac{1}{2 \tilde{\beta}}\left(1+\tilde{\beta}(1-\delta)+\frac{\theta}{\gamma \kappa_{1}}(1-\tilde{\beta})-\right. \\
& \sqrt{\left.\left(1+\tilde{\beta}(1-\delta)+\frac{\theta}{\gamma \kappa_{1}}(1-\tilde{\beta})\right)^{2}-4 \tilde{\beta}(1-\delta)\right) \in(0,1-\delta)} \\
k_{a} & =\frac{1-\phi}{\frac{\bar{C}}{Y}(1+\phi-\alpha)+\alpha \gamma} \frac{1-\tilde{\beta} \rho_{a}}{\kappa_{1}+(1-\tilde{\beta}) \frac{\theta}{\gamma}+\tilde{\beta} \kappa_{1}\left(1-\delta-k_{h}-\rho_{a}\right)}>0 \\
k_{q} & =-\frac{1}{\gamma} \frac{1-\tilde{\beta}}{(1-\tilde{\beta}) \frac{\theta}{\gamma}+\kappa_{1}\left(1-\tilde{\beta} k_{h}-\tilde{\beta} \delta\right)}<0 \\
k_{\mu} & =\frac{\tilde{\beta} / \gamma}{(1-\tilde{\beta}) \frac{\theta}{\gamma}+\kappa_{1}\left(1-\tilde{\beta} \rho_{\mu}+\tilde{\beta}\left(1-\delta-k_{h}\right)\right)} \frac{(1-\tilde{\beta}) \frac{\theta}{\gamma}+\kappa_{1} \tilde{\beta}\left(1-\delta-k_{h}\right)}{(1-\tilde{\beta}) \frac{\theta}{\gamma}+\kappa_{1}\left(1-\tilde{\beta} k_{h}-\tilde{\beta} \delta\right)}>0
\end{aligned}
$$

where $\tilde{\beta}=(1-\delta) \beta$. We can characterize the flex-price PLM consumption, output and interest rates:

$$
\begin{aligned}
\frac{c_{t}^{n, P L M}-c_{t}^{n, R E}}{\kappa_{1}} & =-\left(k_{a}-k_{a}^{R E}\right) a_{t}-\left(k_{h}-k_{h}^{R E}\right) h_{t-1}+ \\
& \left(1-\delta-k_{h}^{R E}\right)\left(h_{t-1}^{n, P L M}-h_{t-1}^{n, R E}\right)-k_{q} q_{t}-k_{\mu} \hat{\mu}_{t-1} \\
\frac{y_{t}^{n, P L M}-y_{t}^{n, R E}}{\frac{\bar{Q} \bar{H}}{\bar{Y}}-\frac{\bar{C}}{Y} \kappa_{1}} & =-\frac{c_{t}^{n, P L M}-c_{t}^{n, R E}}{\kappa_{1}} \\
-\frac{r_{t}^{n, P L M}-r_{t}^{n, R E}}{\gamma \kappa_{1}} & =-\left(\left(1-k_{h}\right)\left(1-\delta-k_{h}\right)-\left(1-k_{h}^{R E}\right)\left(1-\delta-k_{h}^{R E}\right)\right) h_{t-1} \\
& -\left(1-k_{h}^{R E}\right)\left(1-\delta-k_{h}^{R E}\right)\left(h_{t-1}^{n, P L M}-h_{t-1}^{n, R E}\right) \\
& +\left(k_{a}\left(2-\delta-k_{a}-\rho_{a}\right)-k_{a}^{R E}\left(2-\delta-k_{a}^{R E}-\rho_{a}\right)\right) a_{t} \\
& +\left(k_{\mu}\left(2-\delta-k_{h}-\rho_{\mu}\right)-k_{q}\right) \hat{\mu}_{t-1}+k_{q}\left(1-\delta-k_{h}\right) q_{t}
\end{aligned}
$$

In order to find the ALM under flexible prices, we impose market clearing for the durable asset and obtain:

$$
\begin{aligned}
(1-\delta) h_{t-1}+\frac{\omega \delta}{1-\omega} q_{t} & =k_{a} a_{t}+k_{h} h_{t-1}+k_{q} q_{t}+k_{\mu} \hat{\mu}_{t-1} \\
\Leftrightarrow q_{t} & =\frac{1}{\frac{\omega}{1-\omega} \delta-k_{q}}\left(k_{a} a_{t}+k_{\mu} \hat{\mu}_{t-1}-\left(1-\delta-k_{h}\right) h_{t-1}\right) .
\end{aligned}
$$

The equilibrium price is increasing in productivity, increasing in asset price beliefs, and decreasing in the existing stock of housing. 
When the equilibrium asset price $q_{t}$ from equation (130) is substituted into the expression for the natural rate $r_{t}^{n, P L M}$, the natural real rate in the ALM $r_{t}^{n, A L M}$ is increasing in asset price expectations $\hat{\mu}_{t-1}$, just as in the baseline model. The sign of the other coefficients are ambiguous and depend on the parameterization. 